\title{
Tropical Pacific SST Drivers of Recent Antarctic Sea Ice Trends $\mathscr{O}$
}

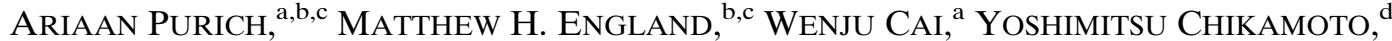

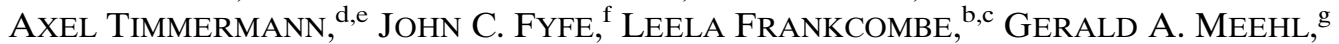 \\ AND JULIE M. ARBLASTER ${ }^{\text {g,h }}$ \\ ${ }^{\text {a } C S I R O}$ Oceans and Atmosphere, Aspendale, Victoria, Australia \\ ${ }^{\mathrm{b}}$ Climate Change Research Centre, University of New South Wales, Sydney, New South Wales, Australia \\ ${ }^{\mathrm{c}}$ ARC Centre of Excellence for Climate System Science, University of New South Wales, Sydney, \\ New South Wales, Australia \\ dinternational Pacific Research Center, University of Hawai'i at Mānoa, Honolulu, Hawaii \\ ${ }^{\mathrm{e}}$ Department of Oceanography, University of Hawai'i at Mānoa, Honolulu, Hawaii \\ ${ }^{\mathrm{f}}$ Canadian Centre for Climate Modelling and Analysis, Environment and Climate Change Canada, \\ Victoria, British Columbia, Canada \\ ${ }^{\mathrm{g}}$ National Center for Atmospheric Research, Boulder, Colorado \\ ${ }^{\mathrm{h}}$ School of Earth, Atmosphere and Environment, Monash University, Clayton, Victoria, Australia
}

(Manuscript received 8 June 2016, in final form 1 September 2016)

\begin{abstract}
A strengthening of the Amundsen Sea low from 1979 to 2013 has been shown to largely explain the observed increase in Antarctic sea ice concentration in the eastern Ross Sea and decrease in the Bellingshausen Sea. Here it is shown that while these changes are not generally seen in freely running coupled climate model simulations, they are reproduced in simulations of two independent coupled climate models: one constrained by observed sea surface temperature anomalies in the tropical Pacific and the other by observed surface wind stress in the tropics. This analysis confirms previous results and strengthens the conclusion that the phase change in the interdecadal Pacific oscillation from positive to negative over 1979-2013 contributed to the observed strengthening of the Amundsen Sea low and the associated pattern of Antarctic sea ice change during this period. New support for this conclusion is provided by simulated trends in spatial patterns of sea ice concentrations that are similar to those observed. These results highlight the importance of accounting for teleconnections from low to high latitudes in both model simulations and observations of Antarctic sea ice variability and change.
\end{abstract}

\section{Introduction}

The dipole pattern of recent Pacific sector sea ice trends, with decreasing ice in the Bellingshausen Sea and increasing ice in the Ross Sea, has been attributed to changing winds (Holland and Kwok 2012; Fan et al. 2014) and specifically to the strengthening of the Amundsen Sea low (Turner et al. 2009, 2016; Clem and Fogt 2015; Clem and Renwick 2015; Meehl et al. 2016a; Raphael et al.2016). There is some suggestion that recent increasing Antarctic sea ice trends since 1979 can be explained by

Supplemental information related to this paper is available at the Journals Online website: http://dx.doi.org/10.1175/JCLI-D-16-0440.s1.

Corresponding author address: Ariaan Purich, CSIRO Oceans and Atmosphere, PMB 1, Aspendale VIC 3195, Australia. E-mail: ariaan.purich@csiro.au interdecadal variability (Fan et al. 2014; Gagné et al. 2015), particularly arising from the phase change of the interdecadal Pacific oscillation (IPO) to negative after the late 1990s (Meehl et al. 2016a), rather than by direct anthropogenic forcing. As such, it is pertinent to scrutinize the proposed causes of these trends. Here we further examine the concept that recent trends in tropical SST and tropical-to-extratropical teleconnections influenced the Amundsen Sea low, thus contributing to the observed pattern of Antarctic sea ice trends. The goal of this study is to address and quantify the influence of tropical Pacific sea surface temperature (SST) variability on Antarctic sea ice trends, specifically focusing on the role of the IPO.

Tropical Pacific SST variability influences the Amundsen Sea low via convectively generated atmospheric Rossby wave trains, including the well-known Pacific-South American (PSA) pattern (Hoskins and Karoly 1981; 
Mo and Higgins 1998; Mo 2000; Yuan and Martinson 2000; Irving and Simmonds 2016) as well as a meridionally oriented wave train during spring (Clem and Fogt 2015). Through its influence on equatorial and off-equatorial convection, El Niño-Southern Oscillation (ENSO) teleconnections to Antarctic sea ice have been previously noted. La Niña is associated with a strengthened Amundsen Sea low, causing increased sea ice in the eastern Ross and Amundsen Seas as a result of increased southerly flow at the surface, and decreased sea ice in the Bellingshausen Sea as a result of increased northerly flow in this region, and vice versa for El Niño (Renwick 2002; Turner 2004; Stammerjohn et al. 2008; Ciasto and England 2011; L'Heureux and Thompson 2006; Simpkins et al. 2012; Ciasto et al. 2015). There are seasonal variations in the ENSO teleconnection, with a link between El Niño and the negative southern annular mode (SAM; and La Niña and the positive SAM) present during austral summer but not during austral winter (e.g., L'Heureux and Thompson 2006; Simpkins et al. 2012). The magnitude of atmospheric circulation anomalies associated with ENSO are roughly comparable for all seasons (relative to the seasonal cycle of ENSO) although are strongest during austral spring, and the strongest influence on sea ice occurs during austral winter and particularly spring (Jin and Kirtman 2009; Simpkins et al. 2012). There are also differences in the teleconnections for different types of El Niño events (e.g., eastern Pacific vs central Pacific events; Ciasto et al. 2015).

Tropical Pacific SSTs have been connected to sea ice reductions in the Bellingshausen Sea via a strengthened Amundsen Sea low during austral autumn (Ding and Steig 2013). Atmospheric wind forcing associated with ENSO variability has been linked to seasonal sea ice duration trends over 1990-2007 in the Atlantic and Pacific sectors (Matear et al. 2015). Clem and Fogt (2015) found that the negative trend in the Pacific decadal oscillation since 1979 has contributed to the deepening of the Amundsen Sea low during austral spring. Recently, as noted above, Meehl et al. (2016a) have also linked the increase in Ross Sea ice trends to the phase shift of the IPO to negative (below normal tropical eastern Pacific SST on the decadal time scale) that occurred in the late 1990s. Warming of the tropical Atlantic Ocean has also been linked with a deepening Amundsen Sea low and thus to sea ice changes ( $\mathrm{Li}$ et al. 2014, 2015a,b; Simpkins et al. 2014). However, recent evidence has been presented that the dominant forcing since the late 1990s has come from the tropical eastern Pacific with the shift to the negative phase of the IPO at this time (Meehl et al. 2016a).

To date, investigation of changes in the tropical Pacific and Atlantic and their teleconnections to Antarctic sea ice have been tested using atmospheric general circulation models (Li et al. 2014, 2015a,b; Simpkins et al. 2014; Meehl et al. 2016a) and an ocean-ice general circulation model (Matear et al. 2015), potentially neglecting important coupled ocean-atmosphere-ice feedbacks. We note that Simpkins et al. (2012) found no significant relationship between trends in SIC and trends in ENSO over 1980-2008, while Liu et al. (2004) and Yu et al. (2011) found that the trends in the SAM and ENSO produce similar spatial patterns in sea ice compared to the observed trends but explain less than one-third of the magnitude of total SIC trends over 1979-2002 and 1979-2007, respectively. With the additional years in the analysis period assessed here (1979-2013), as well as consideration of the phase change of the IPO over this period in the late 1990s (e.g., Meehl et al. 2016a), it is worth revisiting how changes in the tropical Pacific may have influenced Antarctic sea ice trends. We also attempt to separate the externally forced signal from the signal generated by internal variability in the Pacific, something that was not attempted in previous studies. We examine simulations from two different partially coupled experiments that are forced by observed variability in certain predefined regions (termed "pacemaker" experiments) to investigate how observed tropical Pacific decadal variability affected observed Antarctic sea ice trends. The use of these pacemaker experiments enables an estimate of the role of Pacific Ocean SST variability forcing on SIC trends.

\section{Data and methods}

\section{a. Data and model experiments}

We utilize passive microwave sea ice concentration (SIC) processed using the National Snow and Ice Data Center (NSIDC) bootstrap algorithm (Comiso and Nishio 2008; Meier et al. 2015) and SST from the Hadley Centre Sea Ice and Sea Surface Temperature dataset (HadISST; Rayner et al. 2003). We also assess SIC processed using the NASA team algorithm, as it is possible that spurious trends are present in the bootstrap algorithm dataset (Eisenman et al. 2014) and results are found to be almost identical (not shown). Mean sea level pressure (MSLP) is taken from ERA-Interim (Dee et al. 2011), regarded to be the most reliable reanalysis over Antarctica (Bromwich et al. 2011; Bracegirdle and Marshall 2012) and the Amundsen and Bellingshausen Seas (Bracegirdle et al. 2013).

To estimate the forced SIC and MSLP responses, we use the multimodel mean from phase 5 of the Coupled Model Intercomparison Project (CMIP5). To match observations, CMIP5 data from the historical and representative 
concentration pathway 8.5 (RCP8.5) experiments are concatenated over 1979-2013. The choice of RCP scenario for the time period assessed (i.e., 2006-13) has minimal influence, as all forcing scenarios are very similar over this period. We include all CMIP5 models that have SIC data available for both of these experiments, totaling 87 realizations from 41 CMIP5 models (listed in Table S1 of the supplementary material). Each realization is weighted evenly in the multimodel mean. While the majority of CMIP5 models do not capture the observed increase in Antarctic sea ice, the observed sea ice trend lies within the spread of models (Gagné et al. 2015; Purich et al. 2016), and the large ensemble of realizations provides the best available estimate of forced SIC and MSLP responses.

Ocean assimilation coupled pacemaker experiments are run using the low-resolution Community Earth System Model, version 1.0.3 (CESM1; Shields et al. 2012; Chikamoto et al. 2015a). This version of CESM1 uses the Community Atmosphere Model, version 4 (CAM4), and has atmosphere and land spectral T31 $\left(\sim 3.75^{\circ}\right)$ horizontal resolution and ocean and sea ice of approximately $3.75^{\circ}$ horizontal resolution. CMIP5 anthropogenic and natural forcings are used, based on the CMIP5 historical and RCP4.5 (after 2005) scenarios, including greenhouse gases, aerosols, stratospheric ozone, solar variations, and volcanic eruptions.

The CESM1 pacemaker experiments assimilate observed three-dimensional temperature and salinity anomalies (ORAS4; Balmaseda et al. 2013) into the ocean component of the coupled model. Data in sea ice regions are not assimilated, so temperature anomalies in the sea ice region are not constrained by observations and sea ice variations are completely controlled by the internal dynamics. Because these experiments assimilate anomalies rather than absolute fields, the assimilation takes into account model biases related to the climatology, as well as having an externally forced component. Based on this, the assimilation runs have the same climatology and externally forced component as the historical runs. Therefore, the difference between assimilation runs and historical runs is the first order representation of internal climate variability.

Four CESM1 ensemble experiments with a partial assimilation approach in global or regional oceans similar to Chikamoto et al. (2015b) are conducted for the time period 1979-2013, with 10 ensemble members each:

- historical scenario (CESM1-HIST; historical forcings, no assimilation),

- global ocean assimilation (CESM1-GLOB; historical forcings, with global ocean assimilated, excluding sea ice regions),

- equatorial Pacific Ocean assimilation (CESM1-eqPAC; historical forcings, with the entire equatorial Pacific
Ocean between $10^{\circ} \mathrm{S}$ and $10^{\circ} \mathrm{N}$ assimilated, ${ }^{1}$ remaining ocean unconstrained), and

- Atlantic Ocean assimilation (CESM1-ATL; historical forcings, with Atlantic Ocean between $30^{\circ} \mathrm{S}$ and $70^{\circ} \mathrm{N}$ assimilated, remaining ocean unconstrained).

To complement the CESM1 pacemaker experiments, wind stress assimilation pacemaker experiments are conducted using an updated version of the Second Generation Canadian Earth System Model (CanESM2; Arora et al. 2011) with an improved representation of ocean mesoscale eddy transfer coefficients (Saenko et al. 2016). CMIP5 anthropogenic forcings are applied in all experiments, based on the CMIP5 historical and RCP4.5 (after 2005) scenarios, including greenhouse gases, aerosols, and stratospheric ozone. Half of the ensemble members also include solar variations and volcanic eruptions, while the other half do not. As the influence of these natural forcings over the latter part of the experimental period has been shown to be small (Saenko et al. 2016; Sigmond and Fyfe 2016), the two subsets are combined. As in Sigmond and Fyfe (2016), results are very similar between the two subsets (not shown).

The CanESM2 pacemaker experiments assimilate the wind stress felt by the ocean, using the monthly surface wind stress field from ERA-Interim, which is closely constrained by observations. Three CanESM2 ensemble experiments with surface wind stress assimilation in global or regional oceans as in Saenko et al. (2016) and Sigmond and Fyfe (2016) are conducted for the time period 1979-2012 (note that 2013 is not available for these CanESM2 experiments), with 10 ensemble members each:

- climatology (CanESM2-CLIM; time-varying historical forcings, with annually repeating climatological global wind stress assimilated),

- global wind stress assimilation (CanESM2-GLOB; time-varying historical forcings, with monthly evolving global wind stress assimilated), and

- tropical wind stress assimilation (CanESM2-TROP; time-varying historical forcings, with monthly evolving wind stress between $35^{\circ} \mathrm{S}$ and $35^{\circ} \mathrm{N}$ across all three ocean basins assimilated).

For CanESM2, all experiments include historical forcings, but only the time-varying assimilation experiments include internal variability in the assimilated wind stress field. The experiments have similar although not identical climatologies (CanESM2-CLIM annually repeating wind

\footnotetext{
${ }^{1}$ Note that this differs from the experimental setup of Kosaka and Xie (2013), in which only the eastern equatorial Pacific was assimilated.
} 
(a) SST and MSLP trends

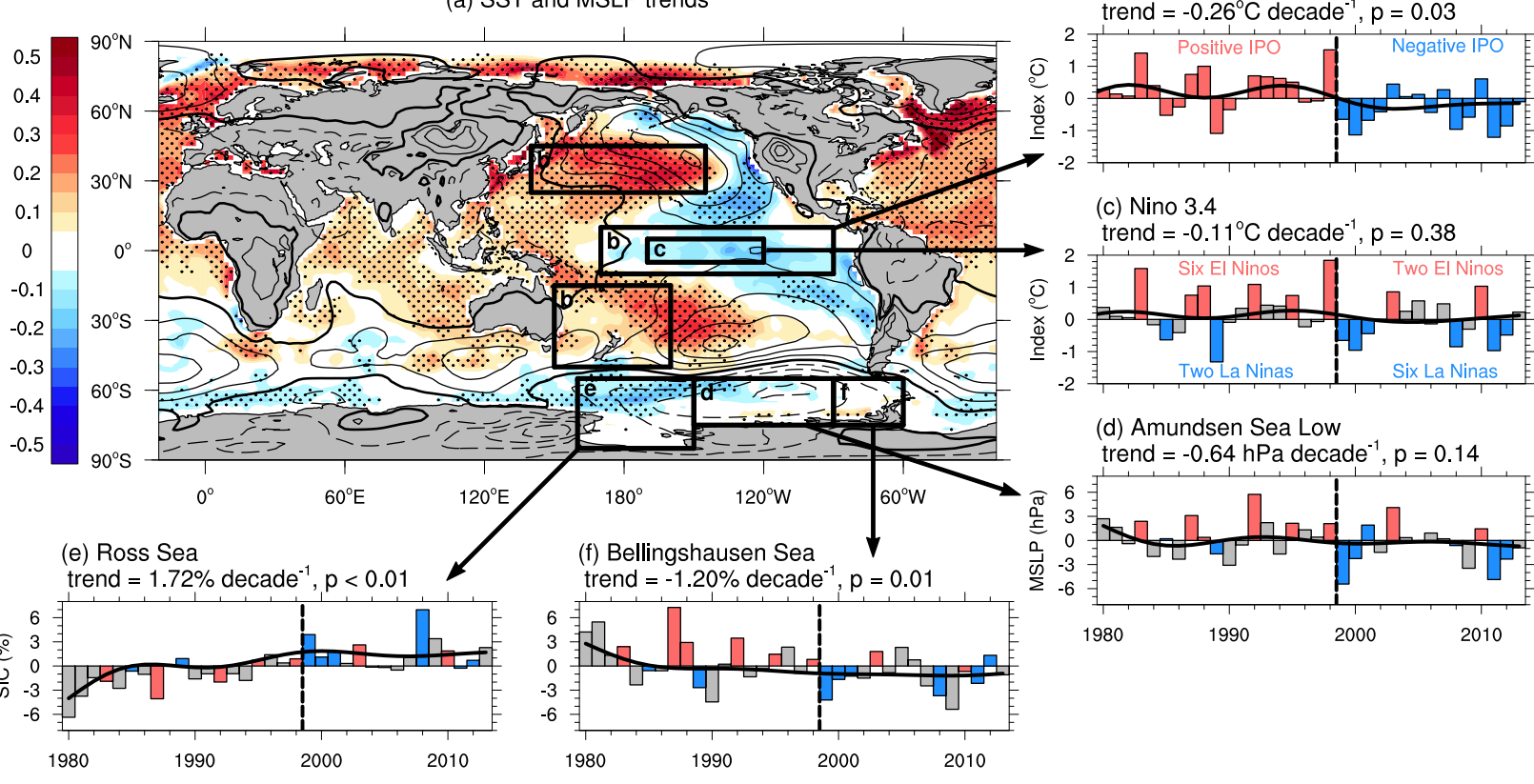

FIG. 1. (a) SST and MSLP trends $\left({ }^{\circ} \mathrm{C}\right.$ and $\mathrm{hPa}$ decade ${ }^{-1}$ ) over 1979-2013. SST is shown in color (blue for negative and red for positive) with MSLP contours overlain [from -2 (dashed) to 2 (solid) by $0.2 \mathrm{hPa}$ decade ${ }^{-1}$, with the zero contour thickened]. Stippling indicates statistical significance of SST trends at the 95\% confidence level using a two-sided Student's $t$ test. Area-averaged time series for the regions indicated by black boxes: (b) unfiltered IPO (positive phase in red and negative phase in blue), with the filtered IPO (calculated from HadISST; Henley et al. 2015) shown by the black curve, (c) Niño-3.4 index, (d) Amundsen Sea low MSLP, (e) Ross Sea SIC, and (f) Bellingshausen Sea SIC. The transition from positive IPO to negative IPO is marked with a dashed black line. In (c)-(f) El Niño events in red, La Niña events in blue, neutral years in gray, and 13-yr low-pass-filtered time series overlain in black.

stress is based on 1979-84, while CanESM2-GLOB and CanESM2-TROP wind stress covers 1979-2012; Fig. S1 in supplementary material). We again assume that the difference between the time-varying assimilation experiments (CanESM2-GLOB and CanESM2-TROP) and the climatology assimilation (CanESM2-CLIM) provides an estimate of the internal variability. This has previously been shown to be reasonable (Sigmond and Fyfe 2016).

\section{b. Analysis methods}

For comparison between observations and models, all data are first bilinearly interpolated to a $2^{\circ} \times 2^{\circ}$ horizontal grid. All data are then annually averaged over the typical ENSO-cycle year (May through to the following April and referred to using the year of the January-April; Fig. 1). This averaging year is chosen to keep ENSO signals together (e.g., Fogt and Bromwich 2006). Data from May 1979 to April 2013 are analyzed (May 1979-April 2012 for CanESM2), and we refer to this period as 1979-2013. The seasonality of teleconnections has previously been shown to be important (e.g., Jin and Kirtman 2009; Li et al. 2014, 2015a,b; Simpkins et al. 2014). Here we focus on the annual average from May to April but have also assessed seasonal averages, which are presented in the supplementary material (see Figs. S2-S9 in supplementary material) and discussed briefly below.

To characterize ENSO we use SST anomalies in the Niño-3.4 region $\left(5^{\circ} \mathrm{S}-5^{\circ} \mathrm{N}, 170^{\circ} \mathrm{E}-120^{\circ} \mathrm{W}\right.$; Fig. 1$)$, with anomalies referenced to the full period, 1979-2013. El Niño and La Niña events are defined here as situations when the Niño-3.4 index exceeds \pm 0.75 standard deviations (based on the full 12-month average; Fig. 1c). Sensitivity to the choice of ENSO index and threshold are tested, and results are found to be robust. To define the IPO we use the tripole index (TPI) as in Henley et al. (2015), calculated as equatorial Pacific SST anomalies $\left(10^{\circ} \mathrm{S}-10^{\circ} \mathrm{N}, 170^{\circ} \mathrm{E}-90^{\circ} \mathrm{W}\right)$ minus averaged midlatitude SST anomalies $\left(25^{\circ}-45^{\circ} \mathrm{N}, 140^{\circ} \mathrm{E}-145^{\circ} \mathrm{W}\right.$ and $50^{\circ}-15^{\circ} \mathrm{S}$, $150^{\circ} \mathrm{E}-160^{\circ} \mathrm{W}$; Fig. 1b). Notably, we do not filter the IPO index. This is because we are interested in both the longterm trend in the IPO, which is in itself a low-pass filter analysis, as well as its interannual variations (e.g., for calculating the interannual regression with SIC). Without filtering, the TPI strongly resembles the Niño-3.4 index (e.g., Newman et al. 2016); however, the TPI also takes into account variability in midlatitude regions (black boxes marked with the letter b in Fig. 1a), important when considering the influence of the tropical Pacific on the high latitudes. Over the period assessed here, while there 
has been no significant trend in the Niño-3.4 index ( $p=$ $0.38)$, there has been a significant trend in the unfiltered IPO TPI ( $p=0.03$; Figs. $1 b, c)$ due to the transition from positive to negative that occurred in the late 1990s (e.g., Lee and McPhaden 2008). Here we assume that the "trend" arises from subsampling multidecadal climate variability, not from changes in external forcing. This is supported by the fact that the historical CMIP5 experiments do not capture a phase shift of the IPO during this time (not shown). As such, there are important differences between the IPO and the Niño-3.4 index emanating from the off-equatorial components of the IPO (Fig. 1a).

Linear trends in SIC and MSLP are calculated using least squares regression. Observed trend significance is determined using a two-sided Student's $t$ test at the 95\% confidence level. Autocorrelation was accounted for by defining the effective sample size $N_{\text {eff }}$ as follows:

$$
N_{\text {eff }}=N\left(1-r_{1}\right) /\left(1+r_{1}\right)
$$

where $N$ is the sample size and $r_{1}$ is the lag- 1 autocorrelation of the detrended SIC time series (Simpkins et al. 2012). The CMIP5 forced response for the period of interest is then subtracted from the observed trends to provide a rough estimate of unforced long-term trends in the observations.

For both CESM1 and CanESM2, trends are calculated for each ensemble member and then averaged (10 runs per ensemble). Ensemble average trend significance is determined when the simulated ensemble mean trend exceeds two standard deviations of individual ensemble member trends ( $\sim 95 \%$ confidence level). Difference trends between assimilation runs and the historical or climatology runs are also calculated for each model (e.g., CESM1-GLOB minus CESM1-HIST). Difference trend significance is determined using the Student's $t$ test to compare two means at the $95 \%$ confidence level.

IPO-related trends in SIC and MSLP are calculated as the IPO trend (arising from internal decadal time-scale variability) multiplied by the regression coefficient between the linearly detrended IPO and linearly detrended SIC or MSLP (e.g., Purich et al. 2013; Clem and Fogt 2015). Significance of the observed IPO-related trends is assessed using a two-sided Student's $t$ test at the 95\% confidence level, testing both the IPO trend and the regression coefficient. Autocorrelation in the regression coefficient significance test was accounted for by defining the effective sample size $N_{\text {eff }}$ as follows:

$$
N_{\text {eff }}=N\left(1-r_{1} r_{2}\right) /\left(1+r_{1} r_{2}\right)
$$

where $N$ is the sample size, $r_{1}$ is the lag- 1 autocorrelation of the detrended SIC time series, and $r_{2}$ is the lag- 1 autocorrelation of the IPO time series (Ciasto and Thompson 2008). Modeled significance is determined when the average modeled trend exceeds two standard deviations of modeled trends ( $\sim 95 \%$ confidence level).

To examine how the modulation of ENSO events via the IPO has contributed to changes in the Amundsen Sea low and to the regional SIC surplus (e.g., Ross Sea) and deficit (e.g., Bellingshausen Sea), observed cumulative maps are calculated for SIC and MSLP. This procedure is similar to calculating composites but without dividing by the number of events. The benefit of using cumulative anomaly maps in this case is that the magnitude of different cumulative anomalies can be directly compared. For example, the cumulative anomalies during all years of the negative phase of the IPO can be directly compared to the cumulative anomalies during only the ENSO years of this IPO phase to see what contribution the ENSO years make to the total cumulative anomalies. Significance is calculated using the Student's $t$ test to compare two means at the $95 \%$ confidence level (e.g., El Niño years vs all years, La Niña years vs all years, and El Niño years vs La Niña years). The sample size is defined as the number of events in the smallest group being compared.

\section{Results}

\section{a. Observed trends}

The observed annual mean SIC trend pattern with the external CMIP5 forcing signal removed ${ }^{2}$ (Fig. 2a) looks similar to the total trend pattern (Fig. 3a). Significant increases in SIC are seen around much of Antarctica (Fig. 2a; magenta shading; Stammerjohn et al. 2008; Holland and Kwok 2012; Simpkins et al. 2012), with a particularly strong increase in the Ross Sea. Smaller areas of significant decreases in SIC are seen in the Amundsen and Bellingshausen Seas (Fig. 2a; green shading). In these areas the observed sea ice decline (Fig. 3a) is stronger than the CMIP5 ensemble trend (Fig. 4a). The observed SIC trend pattern shows similarity to the SIC composite difference pattern for ENSO events (Stammerjohn et al. 2008; Simpkins et al. 2012; Ciasto et al. 2015). This motivates further investigation into the role of the tropical Pacific SST anomalies in influencing Antarctic

\footnotetext{
${ }^{2}$ When removing the external CMIP5 forcing signal, the CMIP5 multimodel mean trend is simply subtracted from the observed trend. As such, Fig. 2a also incorporates the differences in sea ice distributions between the models and observations, although this contributes little to the overall trends displayed.
} 
(a) Observed minus CMIP5 MMM

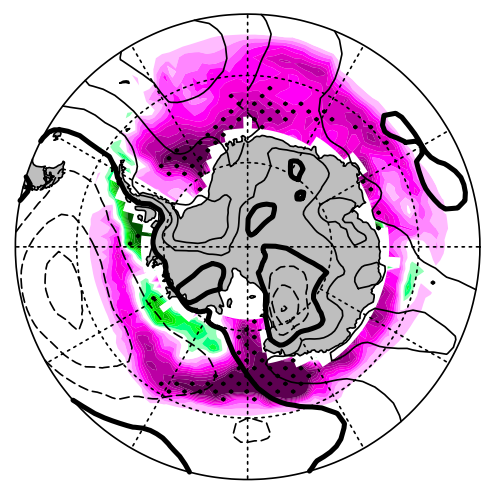

(b) CESM1-GLOB minus HIST

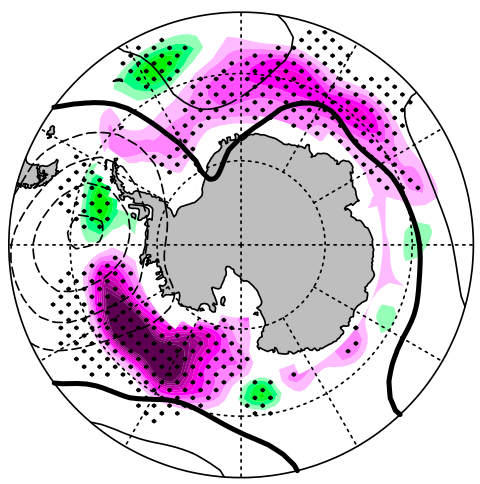

(d) CESM1-eqPAC minus HIST
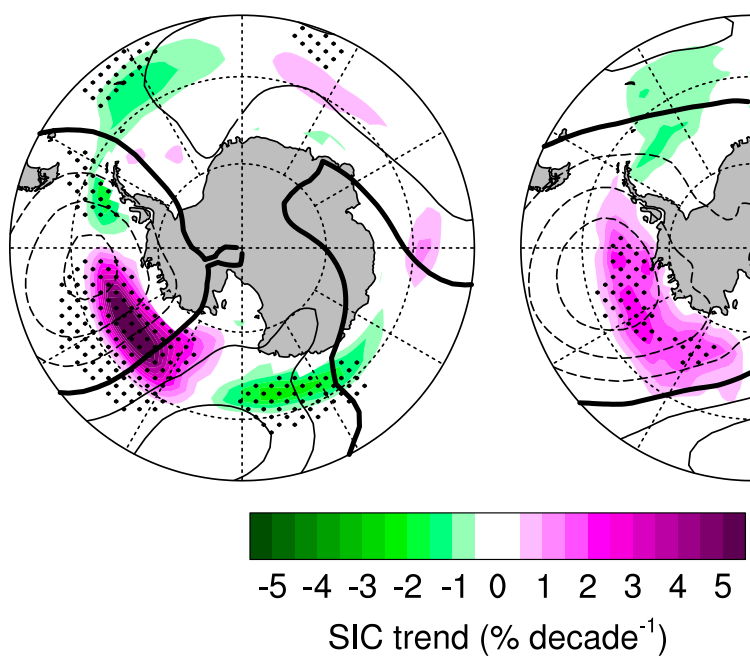

MSLP contours from -2 (dashed) to 2 (solid) by $0.2 \mathrm{hPa}$ decade ${ }^{-1}$

FIG. 2. SIC and MSLP trends ( $\%$ and hPa decade ${ }^{-1}$ ), with trends due to historical forcings removed: (a) observed minus CMIP5 multimodel ensemble, (b) CESM1GLOB minus CESM1-HIST, (c) CanESM2-GLOB minus CanESM2-CLIM, (d) CESM1-eqPAC minus CESM1-HIST, and (e) CanESM2-TROP minus CanESM2CLIM. In all panels, SIC is shown in color (green for negative and magenta for positive) with MSLP contours overlain (dashed for negative, thick for zero, and solid for positive contours). Ensemble average trends are calculated over 1979-2013 using annually averaged SIC. Stippling indicates statistical significance of SIC trends at the $95 \%$ confidence level using a two-sided Student's $t$ test in (a) and using the Student's $t$ test to compare two means in (b)-(e).

(c) CanESM2-GLOB minus CLIM

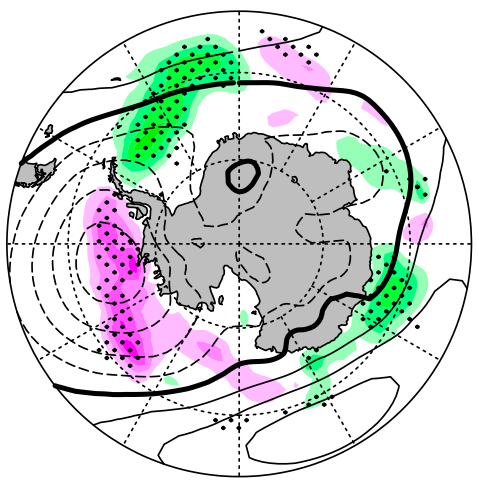

(e) CanESM2-TROP minus CLIM

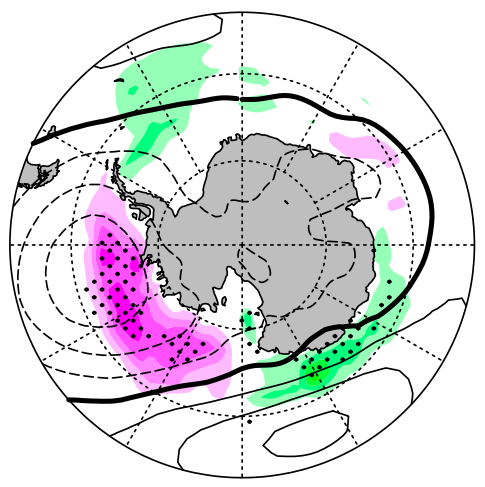$$
\text { (1) }
$$ 
(a) Observed

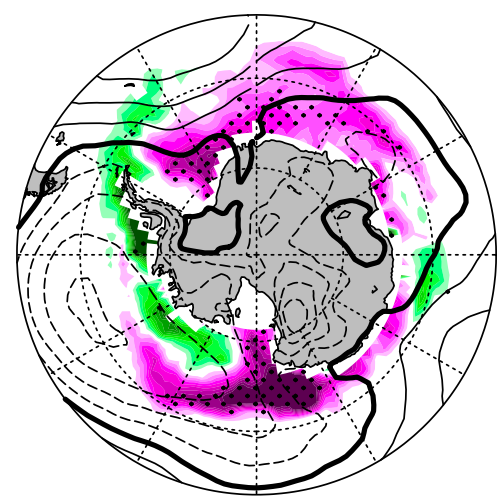

(b) CESM1-GLOB

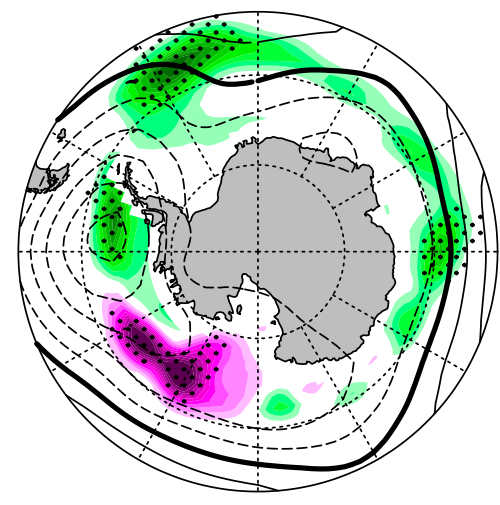

(d) CESM1-eqPAC
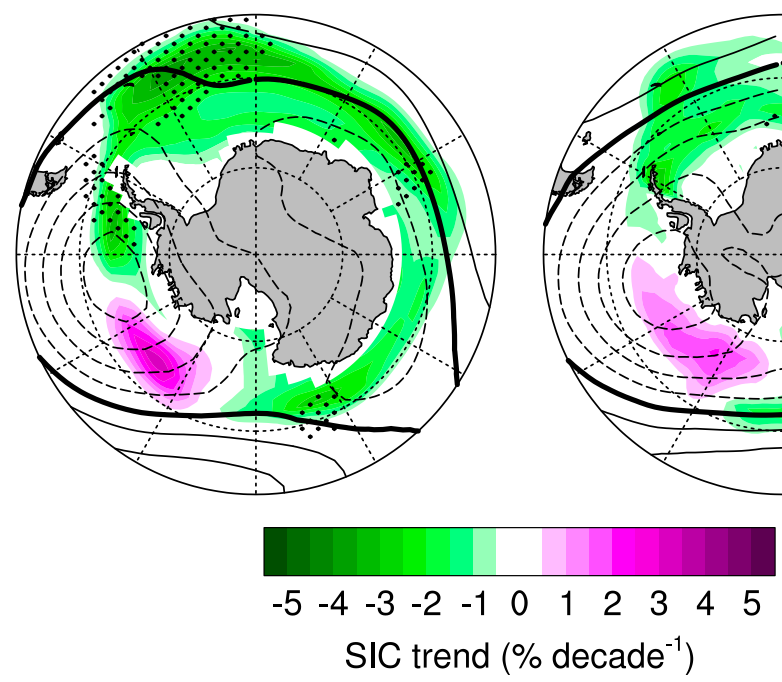

(c) CanESM2-GLOB

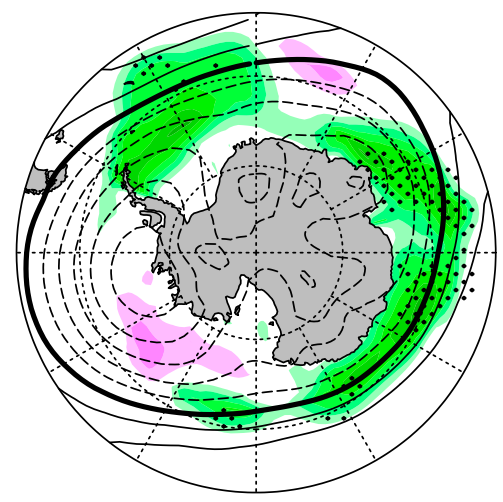

(e) CanESM2-TROP

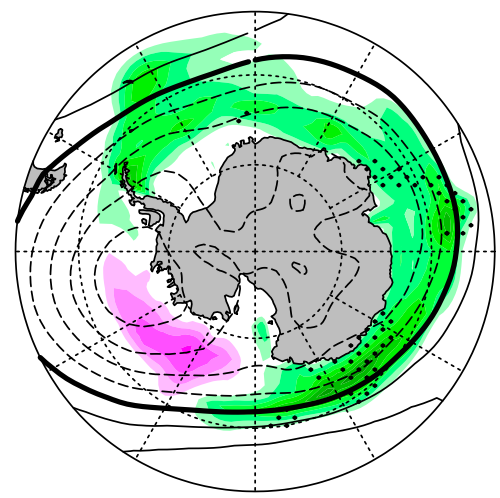


(a) CMIP5 MMM

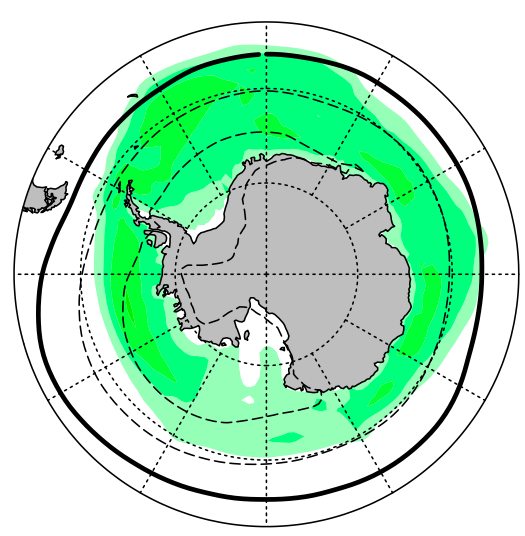

(b) CESM1-HIST

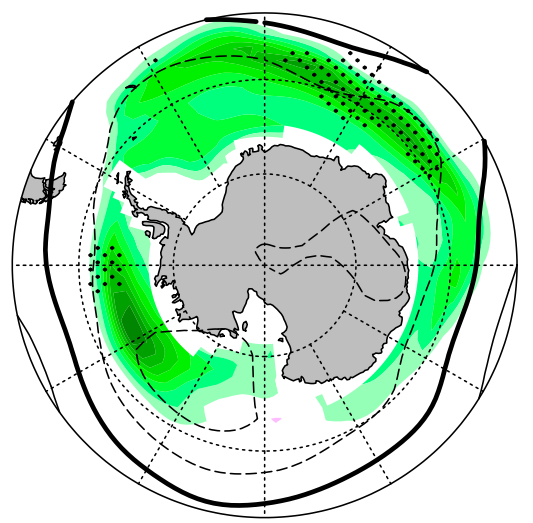

(c) CanESM2-CLIM

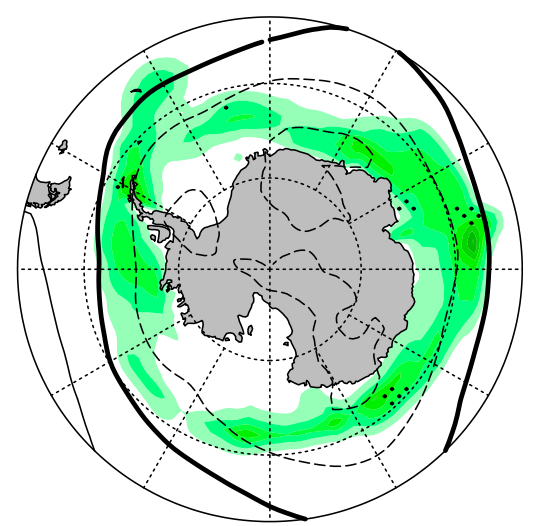

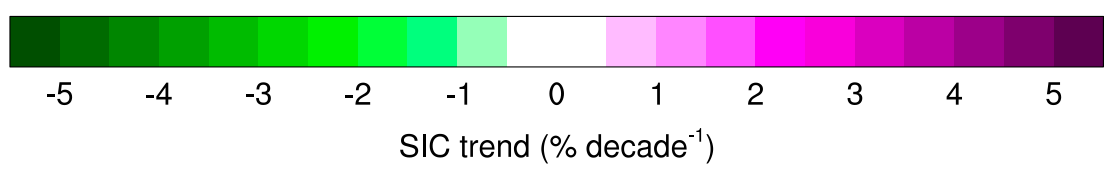

MSLP contours from -2 (dashed) to 2 (solid) by $0.2 \mathrm{hPa}$ decade $^{-1}$

FIG. 4. As in Fig. 2, but showing the SIC and MSLP trends due to historical forcings: (a) CMIP5 multimodel mean, (b) CESM1-HIST, and (c) CanESM2-CLIM.

SIC trends, particularly the dipole SIC trends between the Ross and Bellingshausen Seas.

\section{b. Pacemaker trends}

If decadal SST variability in the tropical Pacific is remotely influencing Antarctic SIC trends via changes to the atmospheric circulation, assuming that atmospheric teleconnections are adequately represented in the models, we would expect that coupled model experiments in which tropical Pacific SST variability matches the observations should simulate SIC trends similar to those observed. Therefore, we next consider the SIC trends from the pacemaker experiments. As described above (section 2a), the ocean assimilation runs have the same climatology and externally forced component as the historical runs. Therefore, we assume that subtracting CESM1-HIST from both CESM1-GLOB and CESM1-eqPAC gives a first-order estimate of the internal (linearly unforced) variability. Similarly, we interpret the difference between CanESM2-GLOB and CanESM2-TROP from CanESM2-CLIM as a rough linear indicator of internal variability with the caveats discussed above. Subtracting out the CESM1-HIST or CanESM2-CLIM trends (Figs. 4b,c) from the assimilation trends (Figs. $3 \mathrm{~b}-\mathrm{e}$ ) thus provides a first-order estimate of the decadal variability without the influence of anthropogenic forcings such as increasing greenhouse gases, aerosols, and stratospheric ozone depletion; that is, this method highlights the influence of tropical teleconnections, as well as the decadal component of the SAM trend due to tropical interactions and intrinsic variability.

We note that the forced trends as simulated by the CMIP5 multimodel mean (Fig. 4a), CESM1-HIST (Fig. 4b) and CanESM2-CLIM (Fig. 4c) are similar, although the CMIP5 multimodel mean is more zonally symmetric, as expected because of averaging across 41 different models. In all panels of Fig. 4, the positive trend in the SAM is seen through the negative MSLP trend encompassing the Antarctic continent. In the CMIP5 multimodel mean there is a circumpolar decrease in SIC, and while there are regions in CESM1HIST and CanESM2-CLIM where there are very weak or no trends in SIC, most regions also show a decrease. As such, subtracting the forced trends (Fig. 4) from the total trends (Fig. 3) to obtain the decadal variability signal (i.e., trends due to internal variability; Fig. 2) has the result of weakening the negative MSLP trends over the Antarctic continent that are also seen in Fig. 3 and of largely reducing the vast areas of total decreasing SIC seen in both the CESM1 (Figs. 3b,d) and CanESM2 (Figs. 3c,e) simulations. Because the CMIP5 multimodel mean SIC trend is largely zonally symmetric (Fig. 4a), subtracting this from the total observed SIC trend (Fig. 3a) does not substantially change the regional pattern of SIC trends in the observed decadal variability signal, although decreases are made weaker and increases are made stronger (Fig. 2a).

CESM1-GLOB decadal variability (minus HIST) signals (Fig. 2b) in SIC and MSLP look qualitatively 
(a) CESM1-ATL minus HIST

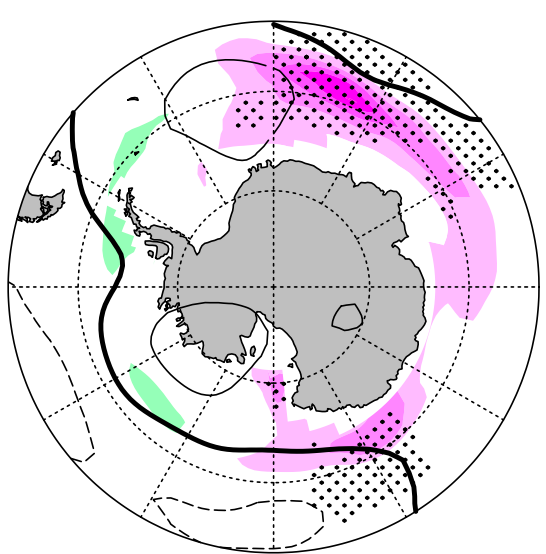

(b) CESM1-ATL

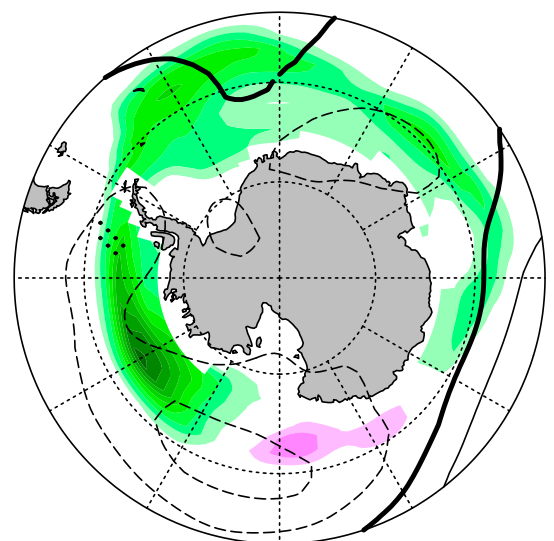

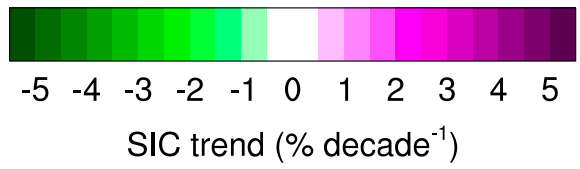

MSLP contours from -2 (dashed) to 2 (solid) by $0.2 \mathrm{hPa}$ decade ${ }^{-1}$

FIG. 5. As in Fig. 2, but showing CESM1 trends from the Atlantic assimilation: (a) CESM1-ATL minus HIST and (b) CESM1-ATL trends (i.e., including trends due to natural variability and historical forcings).

similar to the observed trends (Fig. 2a); there are large regions of increasing SIC in eastern Antarctica and in the eastern Ross and Amundsen Seas (although notably the observed increasing SIC in the western Ross Sea is not captured), while a decrease in SIC is seen in the Bellingshausen Sea. A strengthening of the Amundsen Sea low is apparent; however, the strongest decrease in MSLP is located farther toward the Antarctic Peninsula than observed and does not extend as far west. As a result, the strong increase in the Ross and Amundsen Sea SIC is shifted eastward compared to the satellite data. Meehl et al. (2016a) show that the position of the convective heating anomaly in the tropical Pacific influences the location of the resulting teleconnection, so these biases may be due to differences in the position of tropical Pacific precipitation anomalies between observations and CESM1.

CESM1-eqPAC decadal variability signals (Fig. 2d) show very similar trends in MSLP to CESM-GLOB (Fig. 2b), along with decreasing SIC in the Bellingshausen Sea and increasing SIC in the eastern Ross and Amundsen Seas, suggesting that tropical Pacific variability is driving signals in these regions in CESM1-GLOB (Fig. 2b). The overall MSLP pattern in these experiments is consistent with the PSA pattern. Elsewhere, CESM1-eqPAC trend signals do not resemble CESM1-GLOB signals; however, increasing SIC in CESM1-ATL (Fig. 5) suggests that Atlantic SST anomaly forcing is driving the
CESM1-GLOB signals in the Atlantic and Indian Ocean sectors. Further, while CESM1-eqPAC variability shows a weak decrease in the eastern Ross Sea (Fig. 2d), CESM1ATL variability shows an increase (Fig. 5a). It also appears that CESM1-eqPAC and CESM1-ATL forcings are largely additive (as in Li et al. 2015b), explaining the majority of the decadal SIC signals in CESM1-GLOB. We note that the increase in SIC in the eastern Ross and Amundsen Seas is slightly weaker in CESM1-eqPAC (Fig. 2d) compared to CESM1-GLOB (Fig. 2b), suggesting that a portion of this decadal signal must come from outside of the tropical Pacific and Atlantic Oceans, likely from the extratropics.

In Li et al. (2015b) tropical Atlantic forcing, rather than Pacific forcing, leads to the strongest deepening of the Amundsen Sea low. Li et al. (2015b) use CAM4, the same atmospheric component of CESM used in this study, although at a higher resolution (approximately $2^{\circ}$ horizontal resolution, compared to approximately $3.75^{\circ}$ resolution here) and with a different dynamical core (a finite-volume core, compared to a spectral core here). However, Li et al. (2015b) used Atmospheric Model Intercomparison Project (AMIP)-type specified SST forcing compared to the partially coupled experiments here. Previous studies have suggested the lack of coupling in AMIP-type runs can cause errors in the atmospheric response by responding too strongly in certain regions to SST perturbations (e.g., Barsugli and Battisti 1998). 
In convective heating anomaly experiments designed to specify the actual dynamic heating that forces teleconnections (as opposed to SST), negative convective heating anomalies in the eastern equatorial Pacific (arising from the observed negative phase of the IPO) produced a stronger response in the Amundsen Sea low compared to a positive convective heating anomaly (arising from observed positive tropical Atlantic SSTs; Meehl et al. 2016a). Thus, there are contributions to the deepening of the Amundsen Sea low from convective heating anomalies in both the tropical Atlantic and tropical Pacific, but evidence from Meehl et al. (2016a) shows that the equatorial eastern Pacific makes the larger contribution. Other differences in the dominance of Atlantic or Pacific teleconnections may be due to resolution and/or dynamical differences in the atmospheric model, to differences arising from the coupled system, and/or to differences in the SST fields assimilated (total observed SST, compared to observed SST anomalies here) as well as the differing climatologies that follow.

We next compare results from CESM1 to CanESM2 (Figs. 2c,e). While both models show a strengthening of the Amundsen Sea low, the wave train structure differs. In contrast to the clear PSA pattern displayed by CESM1 (Figs. 2b,d), CanESM2 shows a positive MSLP signal farther west. Both CanESM2-GLOB (Fig. 2c) and CanESM2-TROP (Fig. 2e) show an increase in sea ice in the Amundsen and eastern Ross Seas, as also simulated by CESM1, and the decrease in the western Ross Sea seen in CESM1-eqPAC is also seen in CanESM2-TROP. Whereas CESM1 captures the observed decrease in sea ice in the Bellingshausen Sea, CanESM2 decadal variability shows an increase here but a decrease in the Weddell Sea (CanESM2-GLOB), possibly due to the eastward elongation of the negative MSLP signal. While there are differences in the decadal variability signals of SIC and MSLP between CESM1 and CanESM2, both models capture a strengthening of the Amundsen Sea low and the corresponding increase in sea ice in the Amundsen and eastern Ross Seas.

\section{c. Seasonality of trends}

While our focus is on annual mean trends, patterns do vary seasonally (L'Heureux and Thompson 2006; Simpkins et al. 2012; Ciasto et al. 2015). We briefly discuss the seasonality of the observed and simulated SIC and MSLP trends, noting that trends in CESM1-GLOB and CESM1-eqPAC are largely similar, and likewise for CanESM2-GLOB and CanESM2-TROP; as such, we group the simulations from each model together in our discussion.

Observed decadal variability signals in SIC during austral summer (Fig. S2a) and autumn (Fig. S3a) show decreasing SIC in the Amundsen and Bellingshausen Seas and increases elsewhere. However, CESM1 (Figs. S2b,d and S3b,d) and CanESM2 (Figs. S2c,e and $\mathrm{S} 3 \mathrm{c}, \mathrm{e})$ show an increase in SIC in the Amundsen Sea and little trend in the western Ross Sea. In austral winter (Fig. S4a) and spring (Fig. S5a) the region of observed decreasing SIC shifts eastward to the Antarctic Peninsula, with increases elsewhere. Both models show an increase in SIC in the eastern Ross and Amundsen Seas, and CESM1 shows a decrease in SIC in the Bellingshausen Sea (Figs. S4b,d and S5b,d). The biases in seasonal SIC variability are rendered in the annual mean (Fig. 2).

While a strengthening of the Amundsen Sea low is seen for observations and both CESM1 and CanESM2 in the annual mean (Fig. 2), this signal is largely due to strengthening occurring during austral autumn and winter (Figs. S3 and S4, respectively). During summer, there is a strong positive SAM trend in the forced trends simulated by the CMIP5 multimodel mean, CESM1-HIST, and CESM1-CLIM (not shown). When subtracted to obtain decadal variability, only a weak negative MSLP signal is seen in observations over the eastern Ross Sea (Fig. S2a). In CESM1 there is a weak negative signal located over the Bellingshausen Sea (Fig. S2b,d). In CanESM2, despite removing the SAM trend there is a clear deepening of the Amundsen Sea low (Fig. S2c,e). During autumn, a clear PSA wave train pattern is evident in observations, as also reported in Ding and Steig (2013). Both models capture the PSA pattern, although it is weaker than observed, particularly in CanESM2. In winter the wave train pattern is more meridionally oriented in observations and for CESM1. A similar negative MSLP signal is seen in both models during spring (Fig. S5); however, in observations the signal is centered over the eastern Ross Sea rather than over the Amundsen and Bellinghausen Seas (Fig. S5a). While PSA-like wave trains are shown by CESM1 and CanESM2, a more meridionally oriented wave train is seen in observations (Clem and Fogt 2015).

\section{d. IPO-related sea ice trends}

We next examine the contribution of tropical decadal SST variability on Antarctic sea ice in these pacemaker experiments. Based on the similarity between decadal variability SIC and MSLP signals in the Pacific sector in CESM1-GLOB and CESM1-eqPAC (cf. Figs. 2b and 2d), we focus on tropical Pacific variability. Because of the experimental setup, all tropical variability for CanESM2 is considered (i.e., CanESM2-TROP; including Pacific, Atlantic, and Indian Oceans). We calculate SIC and MSLP trends congruent with decadal variability in the IPO, which is manifested as a trend from positive to negative in subsampling multidecadal variability, using 
(a) Observed

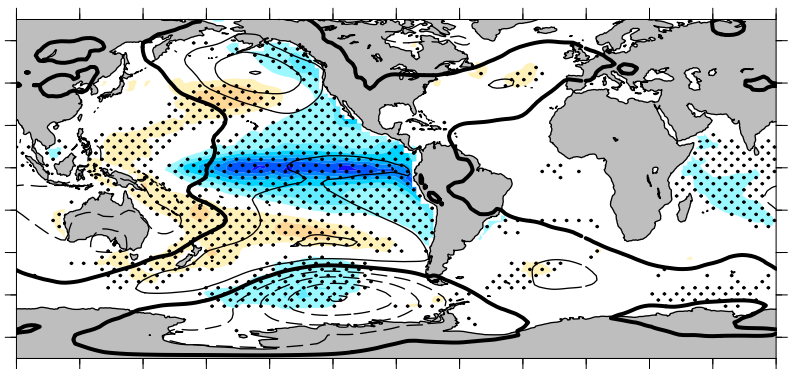

(b) CESM1-GLOB

$\mathrm{r}_{\mathrm{SST}}=0.95, \mathrm{r}_{\mathrm{MSLP}}=0.89$

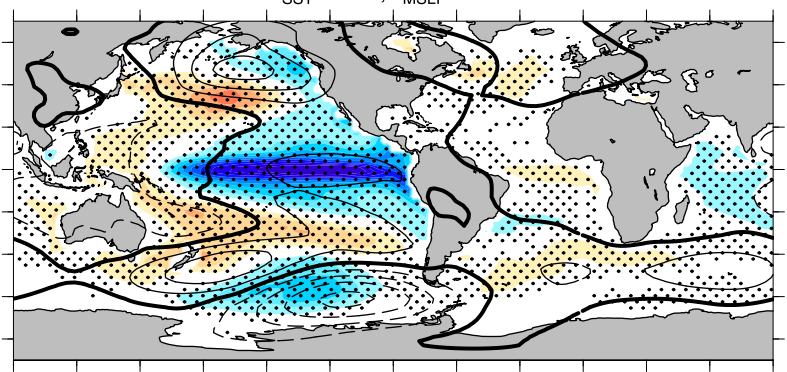

(c) CanESM2-GLOB

$r_{S S T}=0.82, r_{\text {MSLP }}=0.86$
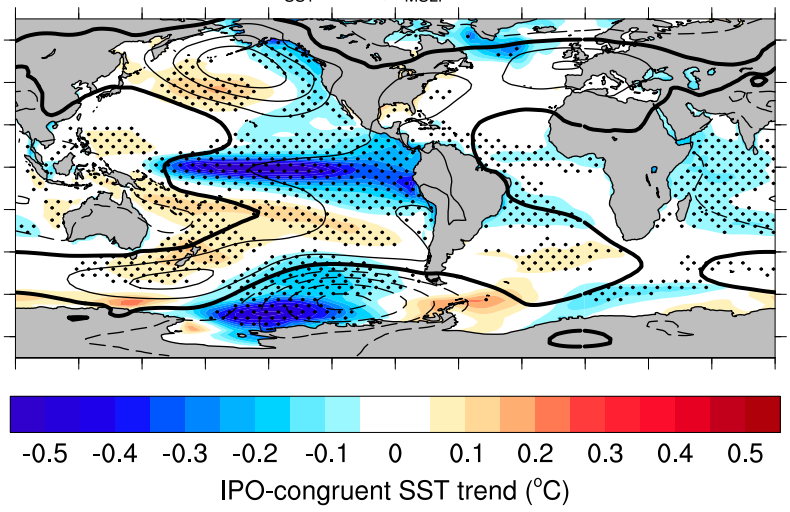

MSLP contours from -2 (dashed) to 2 (solid) by $0.2 \mathrm{hPa}$

FIG. 6. SST and MSLP trends congruent with trends in the IPO because of its transition from positive to negative $\left({ }^{\circ} \mathrm{C}\right.$ and hPa decade ${ }^{-1}$ ): (a) observed, (b) CESM1-GLOB, and (c) CanESM2-GLOB. Congruent trends are calculated over 19792013 as the linear regression of detrended SST onto the detrended IPO, multiplied by the trend in the IPO. In (b), (c), congruent trends are calculated for each ensemble member individually and then averaged across members. Stippling indicates statistical significance of SST trends at the $95 \%$ confidence level, using a two-sided Student's $t$ test in (a) to test significance of both the IPO trend and the regression coefficient and where the ensemble average trend exceeds two standard deviations in (b),(c). Pattern correlations between observed in (a) and modeled trends are calculated over the global domain and indicated above (b),(c).

an unfiltered TPI to represent the IPO. As described above (section $2 \mathrm{~b}$ ), without filtering the TPI strongly resembles the Niño-3.4 index (cf. Figs. $1 b$ and 1c; Newman et al. 2016); however, the TPI also takes into account variability of subtropical and midlatitude regions, which could be potentially important when considering the influence of the tropical Pacific on the high latitudes [such as the influence of the South $\mathrm{Pa}$ cific convergence zone (SPCZ); e.g., Schneider et al. 2012; Clem and Renwick 2015; Meehl et al. 2016a]. As also mentioned above (section $2 \mathrm{~b}$ ), while there has been no significant trend in the Niño-3.4 index, there has been a significant trend in the IPO during the time period under consideration as a result of the transition from the positive phase of the IPO to negative in the late 1990s (Figs. 1b,c). There have also been changes in the frequency (more La Niña than El Niño events; e.g., Ummenhofer et al. 2009) and spatial characteristics (more central Pacific than eastern Pacific El Niño events; e.g., McPhaden et al. 2011) of ENSO. These ENSO changes coincide with the IPO transitioning from the positive to the negative phase (Figs. 1 and 6; Lee and McPhaden 2008; Meehl et al. 2014; Fyfe et al. 2016) and motivate our interest in the significant trend of the IPO.

The observed IPO-related SIC trends (Fig. 7a) show a decrease in the Bellingshausen Sea and an increase in the eastern Ross and Amundsen Seas, in association with a strengthened Amundsen Sea low (Fig. 7a). This pattern is similar to the trend pattern in the Pacific sector (Fig. 1a), albeit weaker, and the region of increasing SIC is shifted eastward. In particular, the IPO-related SIC trends (Fig. 7a) cannot account for the observed increase in the western Ross Sea (Figs. 2a and 3a). CESM1-HIST shows essentially no congruent trends (not shown), as expected because the unconstrained ensemble members all have different phases of the IPO, which cancel out in the ensemble average. This also indicates that the external forcing is not causing one phase of the IPO to be favored. IPO-related SIC and MSLP trends in CESM1-GLOB (Fig. 7b) and CESM1-eqPAC (not shown but similar to Fig. 7b) both agree well with the observations, showing a deepening of the Amundsen Sea low as part of the PSA pattern as well as a corresponding positive SIC trend in the eastern Ross and Amundsen Seas and a negative SIC trend in the Bellingshausen Sea. Further, these IPO-related SIC trends are very similar to the decadal variability signals discussed above (Figs. 1b,c). CanESM2-GLOB (Fig. 7c) and CanESM2-TROP (not shown but similar to Fig. 7c) also show similar IPO-related SIC and MSLP trends. The pattern correlations between simulated and observed congruent trends are high for both models, particularly for MSLP (Fig. 7). The agreement between the IPO-related SIC trends and total SIC trends thus suggest that the IPO is contributing to the regional dipole pattern of SIC trends in the Pacific sector, with the exception of the 
(a) Observed

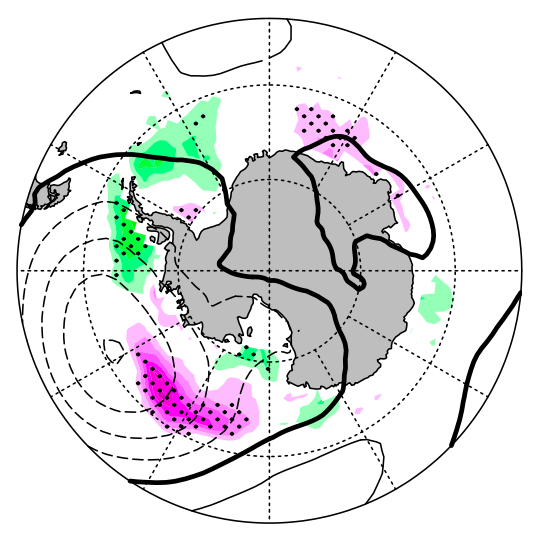

(b) CESM1-GLOB

$\mathrm{r}_{\mathrm{SIC}}=0.68, \mathrm{r}_{\mathrm{MSLP}}=0.94$ (c) CanESM2-GLOB

$r_{\mathrm{SIC}}=0.53, r_{\mathrm{MSLP}}=0.93$
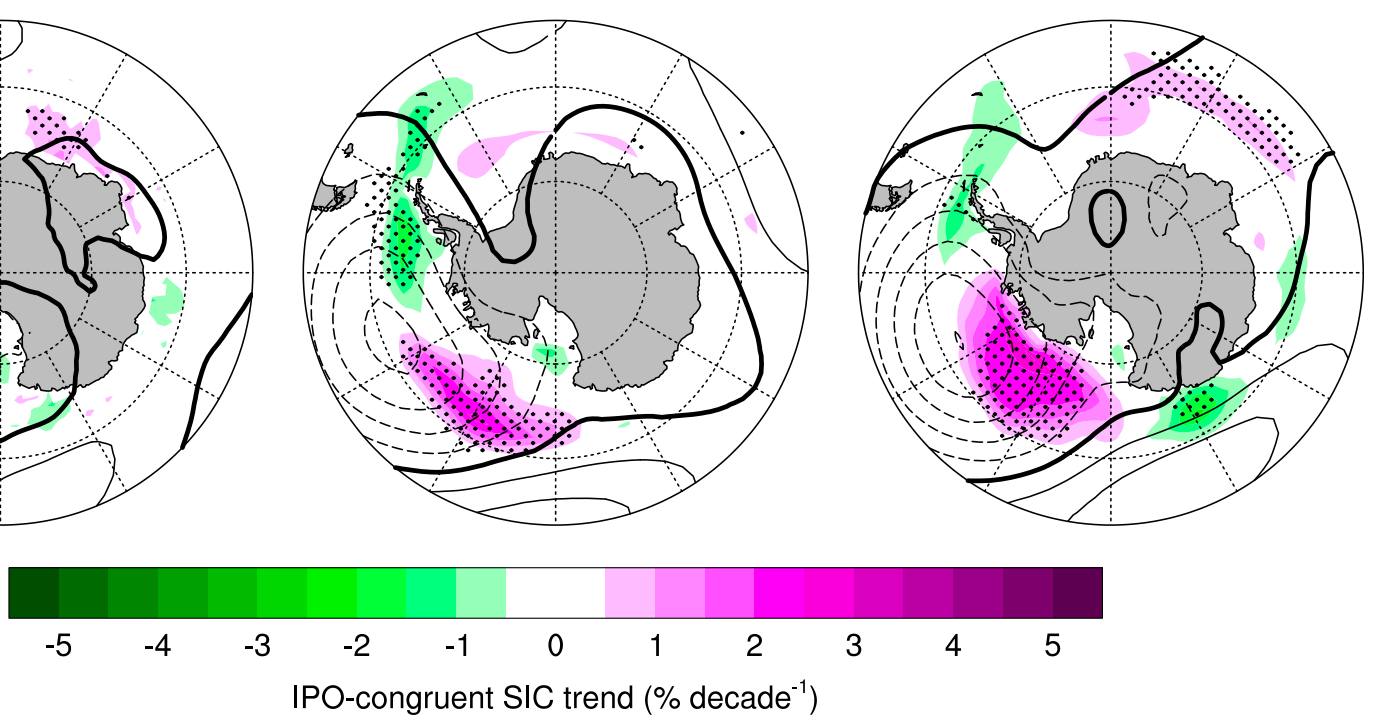

MSLP contours from -2 (dashed) to 2 (solid) by $0.2 \mathrm{hPa}$ decade $^{-1}$

FIG. 7. As in Fig. 6, but for SIC and MSLP trends congruent with trends in the IPO because of its transition from positive to negative $\left(\%\right.$ and $\mathrm{hPa}$ decade $\left.{ }^{-1}\right)$. Pattern correlations are calculated over the domain shown $\left(50^{\circ}-90^{\circ} \mathrm{S}\right)$.

western Ross Sea, where the observed SIC increase is not explained by the IPO or simulated by either model (Figs. 2b,c and 3b,c).

The IPO-related SIC and MSLP trends are largely similar across all seasons (see Figs. S6-S9 in the supplementary material). A strengthened Amundsen Sea low is seen in all seasons, strongest during austral winter and spring in observations and CESM1-GLOB and strongest from austral autumn to spring in CanESM2GLOB. Increased SIC in association with these circulation changes is seen in the eastern Ross and Amundsen Seas in all seasons for observations, CESM1-GLOB, and CanESM2-GLOB. Decreased SIC in the Bellingshausen Sea is also seen for most seasons and across the observations and both models; however, it often lacks significance and is not seen for CanESM2-GLOB during austral summer (Fig. S6c). Overall, the strong agreement between the observations, CESM1, and CanESM2 and the similarity in IPO-related SIC trends across the seasons strengthens the conclusions made above regarding the annual-mean IPO-related trends.

\section{e. IPO modulation of ENSO teleconnection}

Meehl et al. (2016a) proposed that Ross Sea SIC trends have been influenced by the phase shift of the IPO (Fig. 1b). In their study, they find that changes in precipitation and convective heating primarily in the eastern Pacific and secondarily in the SPCZ region associated with the phase shift of the IPO in the late 1990s force anomalous Rossby waves, teleconnecting to the Amundsen Sea low and causing a strengthening (as also described in Schneider et al. 2012; Clem and Renwick 2015). From this, they infer that changes in the geostrophic wind result in more southerly flow over the Ross Sea, leading to increased sea ice in this region. In addition to increased Ross Sea ice, other studies relating the strengthened Amundsen Sea low to Antarctic sea ice trends also find reduced sea ice in the Bellingshausen Sea because of increased northerly flow, (e.g., Li et al. 2014; Simpkins et al. 2014). We have confirmed here that the regional SIC trend characteristics associated with the IPO are a result of a deepening of the Amundsen Sea low (Fig. 7).

As described above (section 1), the ENSO teleconnection to Antarctic sea ice has been widely studied (e.g., Renwick 2002; Stammerjohn et al. 2008; Simpkins et al. 2012; Ciasto et al. 2015). Despite no significant trend in the Niño-3.4 index over 1979-2013, during the positive phase of the IPO more El Niño events occurred (between 1979 and 1998 there were six El Niño and two La Niña events; Fig. 1c), whereas during the negative phase of the IPO more La Niña events occurred (between 1999 and 2013 there were two El Niño and six La Niña events; Fig. 1c). Through Rossby wave train teleconnections to the Southern Hemisphere, a change in the frequency and spatial character of ENSO could impact the strength of the Amundsen Sea low (Fig. 1d), which may lead to a rectification and a net 
surplus or deficit of SIC in different regions over 1979-2013 (Figs. 1e,f). Over 1990-2007, Matear et al. (2015) found that wind forcing associated with ENSO contributed to sea ice duration trends in both the eastern and western Pacific sectors, further motivating examination of the ENSO contribution over the longer period here.

Comparing the cumulative anomalies of observed SIC and MSLP during the positive phase of the IPO with those during only ENSO years of the positive IPO (cf. Figs. 8a and 8d), it is clear that the two patterns are similar to each other, dominated by El Niño (Fig. 9a). Likewise, the cumulative anomalies during the negative phase of the IPO are similar to those during only ENSO years of the negative IPO (cf. Figs. $8 \mathrm{~b}$ and $8 \mathrm{e}$ ), dominated by La Niña (Fig. 9b). Following on, comparing their difference patterns (i.e., negative IPO minus positive IPO; negative IPO ENSO events minus positive IPO ENSO events; cf. Fig. $8 \mathrm{c}$ and $8 \mathrm{f}$ ) shows that the ENSO cumulative anomaly pattern difference is very similar to the corresponding IPO cumulative anomaly difference and is dominated by the difference between El Niño and La Niña (Fig. 9c). We note that these results should be considered with caution, as there is a trend in the IPO as well as the SIC and MSLP time series used in this analysis. However, repeating the analysis with linearly detrended time series (not shown) finds that the spatial pattern of cumulative SIC anomalies in the eastern Ross, Amundsen, and Bellingshausen Seas that occur during the two phases of the IPO are largely explained by the ENSO events in these phases. This supports the interpretation of Fig. 8.

The total SIC trends resulting from the impact of IPO can also be understood via the unequal number of El Niño and La Niña events during each IPO phase; that is, more El Niño events during positive IPO and more La Niña events during negative IPO, as well as a change in the nature of events (Ashok et al. 2007; McPhaden et al. 2011). Furthermore, the ENSO teleconnection to high latitudes appears nonlinear and asymmetric with respect to El Niño and La Niña (Figs. 8d,e; also noted by Ciasto et al. 2015). As such, the cumulative impacts from El Niño and from La Niña do not completely offset but rectify into mean changes. These mean changes are especially conspicuous when there are more El Niño events during positive IPO and more La Niña events during negative IPO (Fig. 8f). The difference between the cumulative impact during the negative IPO phase and during the positive IPO phase accounts for a large portion of the trend, suggesting that the influence of the IPO on the Amundsen Sea low and SIC is overall manifest via its association with an unequal number of
El Niño and La Niña events during the two phases of the IPO.

\section{Discussion}

Since regular satellite observations became available in 1979, Antarctic SIC has increased in most regions, despite greenhouse warming over the same period (Cavalieri and Parkinson 2008; Comiso and Nishio 2008; Parkinson and Cavalieri 2012) and multimodel averages that show decreasing SIC. A particularly large increase in sea ice has been observed in the Ross Sea, although sea ice has been declining near the Antarctic Peninsula in the Amundsen and Bellingshausen Seas (Stammerjohn et al. 2008; Holland and Kwok 2012; Simpkins et al. 2012). Utilizing coupled pacemaker experiments we provide further evidence in support of internal decadal climate variability associated with the IPO as a driving influence on Antarctic sea ice trends in the Pacific sector, specifically in the eastern Ross, Amundsen, and Bellingshausen Seas. We note, however, that the IPO cannot account for sea ice trends in the western Ross Sea. Our analysis suggests that tropical Pacific SST anomalies associated with the IPO and ENSO contribute to the rectification of observed trends on Antarctic sea ice.

The pacemaker experiments assessed here are based on coupled atmosphere-ocean-sea ice models, which differ from previous studies using atmospheric-only models (Li et al. 2014, 2015a,b; Simpkins et al. 2014; Meehl et al. 2016a). This is notable because, although these studies suggest that a strengthening of the Amundsen Sea low due to tropical teleconnections can be linked to observed changes in the sea ice, the sea ice response is not directly simulated in the latter.

The majority of CMIP5 models simulate a decline in Antarctic sea ice extent (Turner et al. 2013; Zunz et al. 2013), and while the overall observed trend has been shown to lie within modeled variability (Mahlstein et al. 2013; Polvani and Smith 2013; Swart and Fyfe 2013; Turner et al. 2013; Zunz et al. 2013), when the regionality of sea ice trends is accounted for, trends during austral summer and autumn are outside the modeled range of variability (Hobbs et al. 2015). As with the majority of CMIP5 models, CESM1-HIST and CanESM2-CLIM lose too much sea ice compared to observations. However, CMIP5 ensemble members that happened to match the timing of the negative phase of the IPO also simulated an increase of Antarctic sea ice during the early 2000s (Meehl et al. 2014).

In both the CESM1 and CanESM2 assimilation experiments, the strengthened Amundsen Sea low associated with the phase shift of the IPO results in an increase in sea ice in the eastern Ross and Amundsen Seas; however, this 
(a) +IPO (19 years)

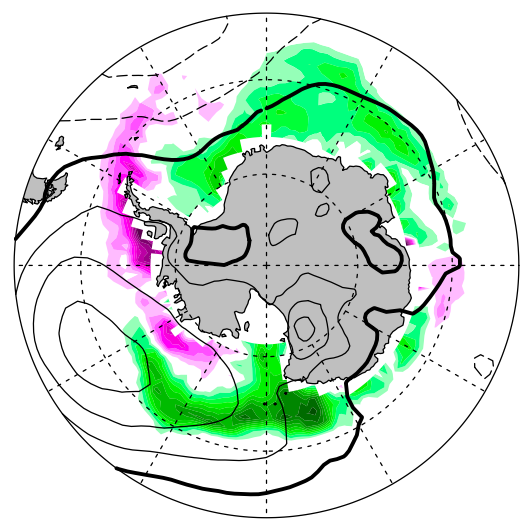

(d) +IPO ENSO (6 EN + 2 LN)

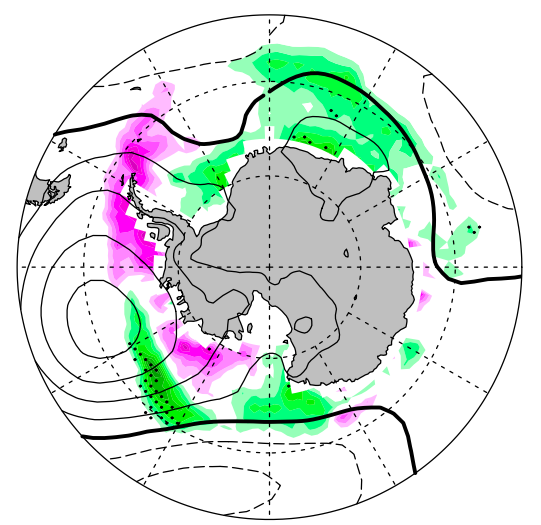

(b) -IPO (15 years)

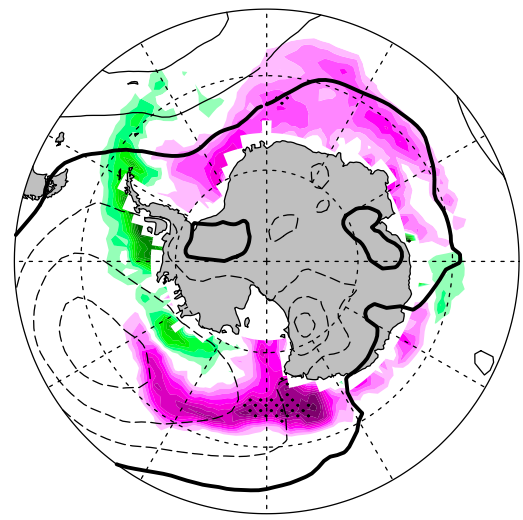

(e) - IPO ENSO (2 EN + 6 LN)

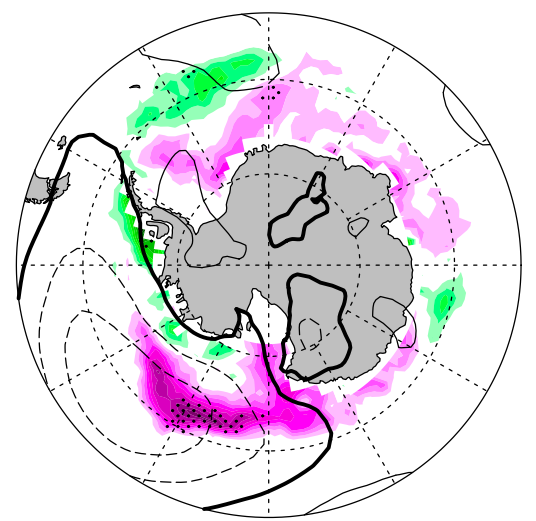

(c) -IPO minus +IPO (b minus a)

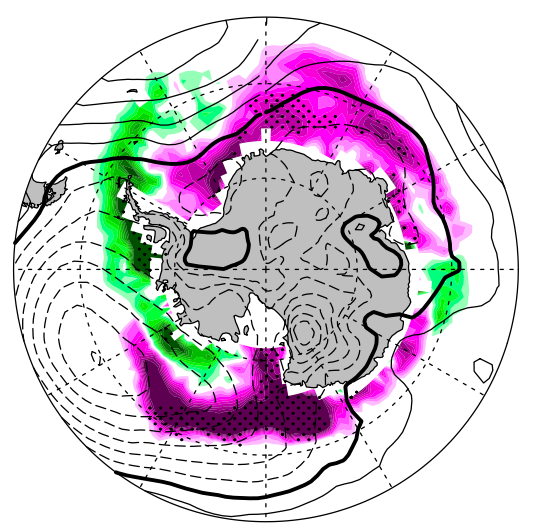

(f) ENSO difference (e minus d)
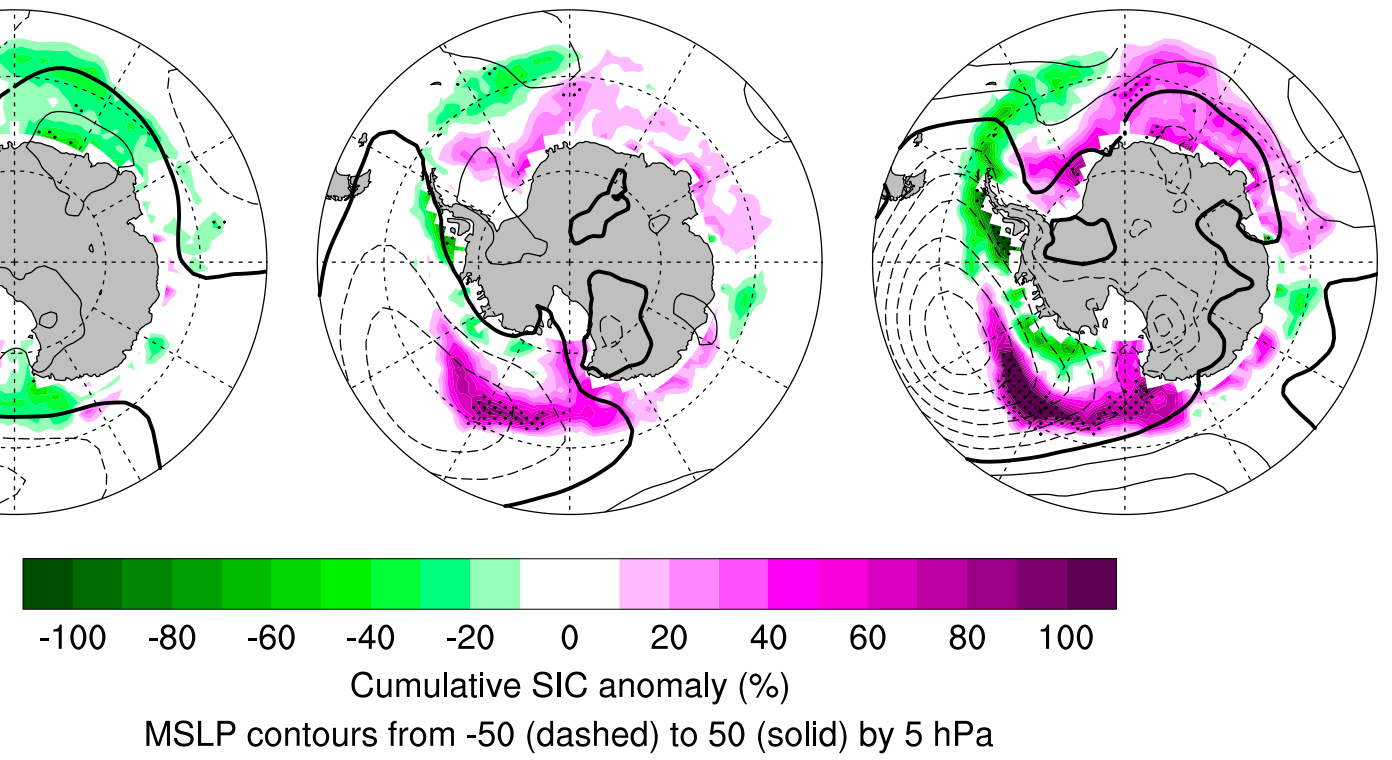

MSLP contours from - 50 (dashed) to 50 (solid) by $5 \mathrm{hPa}$

FIG. 8. Observed SIC and MSLP cumulative anomalies (\% and hPa): (a) positive IPO (1979-99), (b) negative IPO (2000-13), (c) IPO difference [(b) minus (a)], (d) ENSO years during positive IPO (six El Niño and two La Niña events), (e) ENSO years during negative IPO (two El Niño and six La Niña events), and (f) ENSO difference [(e) minus (d)]. Cumulative anomalies are calculated as the sum of SIC and MSLP anomalies during specified events, without normalizing by the number of events. Stippling indicates statistical significance of cumulative SIC anomalies at the 95\% confidence level using the Student's $t$ test to compare two means: comparing the select events to all years in (a),(b),(d),(e) and comparing the two differenced groups in (c),(f).

increase is weaker than observed. Further, neither model captures the strong observed increase in sea ice in the western Ross Sea, and, because of the lack of IPO-related sea ice trends in this region even in observations (Fig. 7a), it is unlikely that trends in this region are linked to the IPO phase change. Sea ice increases elsewhere around Antarctica are also not simulated in these models. Based on the assessment of decadal variability signals it appears that the CESM1 and CanESM2 assimilation experiments capture the observed variability well, but one interpretation is that greenhouse warming overwhelms the total trends in SIC in these experiments. Another possibility is that the locations of anomalous precipitation and convective heating anomalies may not be in the same locations or magnitudes as observed. It could be possible that either Antarctic sea ice variations in both CESM1 and CanESM2 are too sensitive to global warming or that these models underestimate the amplitude of decadal variability of Antarctic sea ice by an overly damped response to tropical Pacific variability. A damped response may be the result of the cold SST bias in both models in the SPCZ region, suppressing 
(a) El Nino (8 years)

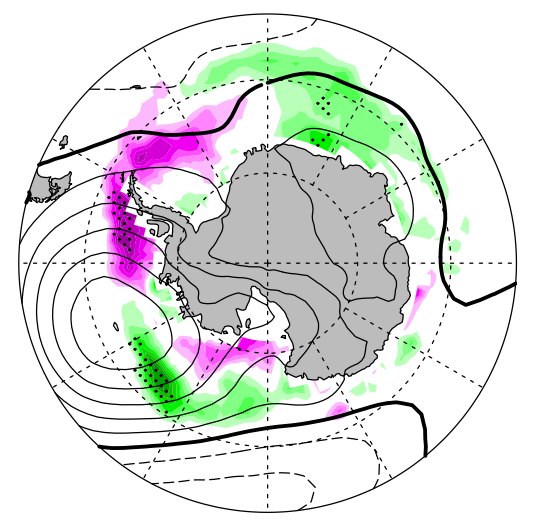

(b) La Nina (8 years)

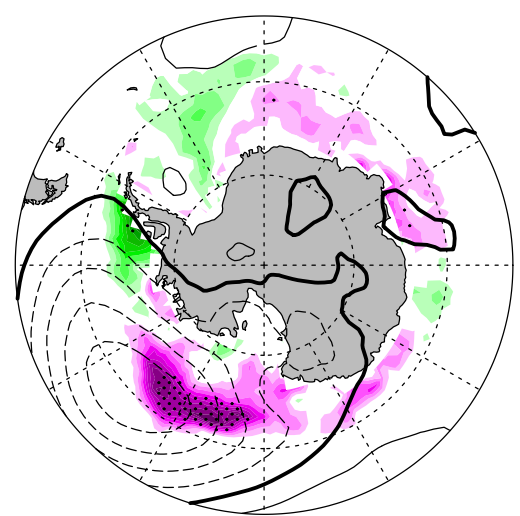

(c) La Nina minus El Nino (b minus a)
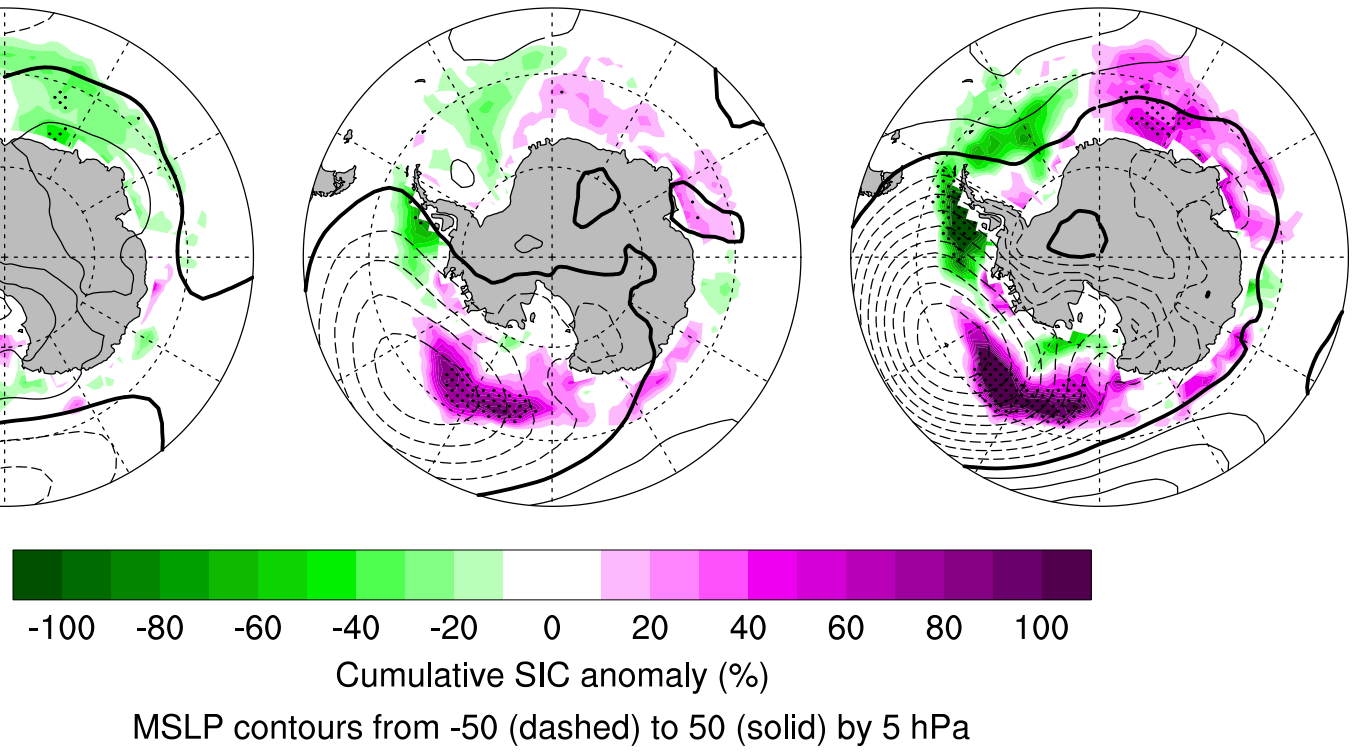

100

MSLP contours from -50 (dashed) to 50 (solid) by $5 \mathrm{hPa}$

FIG. 9. As in Fig. 8, but showing cumulative anomalies for (a) El Niño, (b) La Niña, and (c) La Niña minus El Niño [(b) minus (a)].

convection there and damping the remote atmospheric response because it has been shown that positive SST, precipitation, and convective heating anomalies there during negative IPO can contribute to a deepening of the Amundsen Sea low (Clem and Renwick 2015; Meehl et al. 2016a). More realistic simulations of recent Antarctic sea ice variations could thus be achieved by improving model deficiencies involved in the climate response to external forcings and the remote impact of tropical regions. Other caveats include issues with how sea ice is modeled in current coupled climate models and how the simulated sea ice interacts with ocean and surface air temperatures and winds.

Because of the various feedbacks between sea ice and the climate system (e.g., Goosse and Zunz 2014), assessing coupled models is important to fully understand how tropical teleconnections influence Antarctic sea ice. For example, while changed surface wind trends may be conducive to a sea ice increase in the Ross Sea, it is likely that a net SST cooling is also required for sea ice to increase and to accurately capture positive ice-albedo and ocean thermal warming feedbacks (Stammerjohn et al. 2012). For both CESM1 and CanESM2, the assimilation experiments show less ice loss in most sectors than their corresponding CESM1-HIST or CanESM2-CLIM experiments but not a net ice increase. Without simulating the correct sign of observed sea ice changes, positive feedbacks will reinforce the ice loss, rather than the ice growth, propagating differences (e.g., Purich et al. 2016).

Finally, we note that a number of previous studies have found teleconnections from the tropical Atlantic to the Amundsen Sea low to be important in driving Ross and Bellingshausen Seas sea ice changes (Li et al. 2014, 2015a,b; Simpkins et al. 2014). Therefore, it is likely that details of the decadal patterns of tropical SST, precipitation, and convective heating anomalies, as well as seasonality, are important in model simulations and the observed SIC, at least until 2013. Since the IPO has apparently changed phase around 2014 (Meehl et al. 2016b) the overall trend of SIC should now become less positive and may eventually turn negative on decadal time scales. While Atlantic forcing appears to play a role in influencing sea ice trends in the Atlantic and Indian Ocean sectors, in CESM1 the equatorial Pacific forcing seems to dominate sea ice trends in the Pacific sector. The design of the CanESM2 experiments does not allow for a direct comparison. Further work using coupled models is required to isolate the influences of the tropical Atlantic and Pacific Oceans on different sectors of Antarctic sea ice in a fully coupled framework.

Acknowledgments. This work was supported by CSIRO Oceans and Atmosphere, the Australian Research Council (ARC), including the ARC Centre of Excellence for Climate System Science, and the U.S. National Science Foundation. A. P. was supported by an Australian Postgraduate Award and a CSIRO Office of the Chief Executive Science Leader scholarship. M. H. E. was supported by an ARC Laureate Fellowship. W. C. was supported by the Australian Climate Change Science Programme and a CSIRO Office of the Chief Executive 
Science Leader award. A. T. and Y. C. were supported through a National Science Foundation Award 1049219. G. A. M. and J. M. A. were partially supported by the Regional and Global Climate Modeling Program (RGCM) of the U.S. Department of Energy's Office of Biological and Environmental Research (BER) Cooperative Agreement DE-FC02-97ER62402 and the National Science Foundation. The CESM1 experiments were supported by the University of Southern California Center for HighPerformance Computing and Communications (http:// hpcc.usc.edu/) and the high-performance computing from Yellowstone (http://n2t.net/ark:/85065/d7wd3xhc) provided by NCAR's Computational Information Systems Laboratory sponsored by the National Science Foundation. We thank Rob DeConto for useful discussions on the 2015 tropical to high-latitude teleconnections while M. H. E. attended the SCAR Cross-Program Workshop held in Barcelona in 2015. We also thank Will Hobbs and two anonymous reviewers for their helpful comments, which improved this manuscript. We acknowledge the World Climate Research Programme's Working Group on Coupled Modelling, which is responsible for CMIP, and thank the climate modeling groups for producing and making available their model output.

\section{REFERENCES}

Arora, V. K., and Coauthors, 2011: Carbon emission limits required to satisfy future representative concentration pathways of greenhouse gases. Geophys. Res. Lett., 38, L05805, doi:10.1029/2010GL046270.

Ashok, K., S. K. Behera, S. A. Rao, H. Weng, and T. Yamagata, 2007: El Niño Modoki and its possible teleconnection. J. Geophys. Res., 112, C11007, doi:10.1029/2006JC003798.

Balmaseda, M. A., K. Mogensen, and A. T. Weaver, 2013: Evaluation of the ECMWF ocean reanalysis system ORAS4. Quart. J. Roy. Meteor. Soc., 139, 1132-1161, doi:10.1002/qj.2063.

Barsugli, J. J., and D. S. Battisti, 1998: The basic effects of atmosphereocean thermal coupling on midlatitude variability. J. Atmos. Sci., 55, 477-493, doi:10.1175/1520-0469(1998)055<0477: TBEOAO $>2.0 . \mathrm{CO} ; 2$.

Bracegirdle, T. J., and G. J. Marshall, 2012: The reliability of Antarctic tropospheric pressure and temperature in the latest global reanalyses. J. Climate, 25, 7138-7146, doi:10.1175/ JCLI-D-11-00685.1.

—, E. Shuckburgh, J.-B. Sallee, Z. Wang, A. J. S. Meijers, N. Bruneau, T. Phillips, and L. J. Wilcox, 2013: Assessment of surface winds over the Atlantic, Indian, and Pacific Ocean sectors of the Southern Ocean in CMIP5 models: Historical bias, forcing response, and state dependence. J. Geophys. Res. Atmos., 118, 547-562, doi:10.1002/jgrd.50153.

Bromwich, D. H., J. P. Nicolas, and A. J. Monaghan, 2011: An assessment of precipitation changes over Antarctica and the Southern Ocean since 1989 in contemporary global reanalyses. J. Climate, 24, 4189-4209, doi:10.1175/2011JCLI4074.1.

Cavalieri, D. J., and C. L. Parkinson, 2008: Antarctic sea ice variability and trends, 1979-2006. J. Geophys. Res., 113, C07004, doi:10.1029/2007JC004564.
Chikamoto, Y., and Coauthors, 2015a: Skilful multi-year predictions of tropical trans-basin climate variability. Nat. Commun., 6, 6869, doi:10.1038/ncomms7869.

_ A. Timmermann, S. Stevenson, P. DiNezio, and S. Langford, 2015b: Decadal predictability of soil water, vegetation, and wildfire frequency over North America. Climate Dyn., 45, 2213-2235, doi:10.1007/s00382-015-2469-5.

Ciasto, L. M., and D. W. J. Thompson, 2008: Observations of largescale ocean-atmosphere interaction in the Southern Hemisphere. J. Climate, 21, 1244-1259, doi:10.1175/2007JCLI1809.1.

_ to Southern Ocean SST anomalies diagnosed from a surface mixed layer heat budget. Geophys. Res. Lett., 38, L09701, doi:10.1029/2011GL046895.

_ G. R. Simpkins, and M. H. England, 2015: Teleconnections between tropical Pacific SST anomalies and extratropical Southern Hemisphere climate. J. Climate, 28, 56-65, doi:10.1175/JCLI-D-14-00438.1.

Clem, K. R., and R. L. Fogt, 2015: South Pacific circulation changes and their connection to the tropics and regional Antarctic warming in austral spring, 1979-2012.J. Geophys. Res. Atmos., 120, 2773-2792, doi:10.1002/2014JD022940.

_ circulation and temperature changes and links to the SPCZ. J. Climate, 28, 7371-7384, doi:10.1175/JCLI-D-15-0125.1.

Comiso, J. C., and F. Nishio, 2008: Trends in the sea ice cover using enhanced and compatible AMSR-E, SSM/I, and SMMR data. J. Geophys. Res., 113, C02S07, doi:10.1029/2007JC004257.

Dee, D. P., and Coauthors, 2011: The ERA-Interim reanalysis: Configuration and performance of the data assimilation system. Quart. J. Roy. Meteor. Soc., 137, 553-597, doi:10.1002/qj.828.

Ding, Q., and E. J. Steig, 2013: Temperature change on the Antarctic Peninsula linked to the tropical Pacific. J. Climate, 26, 7570-7585, doi:10.1175/JCLI-D-12-00729.1.

Eisenman, I., W. N. Meier, and J. R. Norris, 2014: A spurious jump in the satellite record: Has Antarctic sea ice expansion been overestimated? Cryosphere, 8, 1289-1296, doi:10.5194/ tc-8-1289-2014.

Fan, T., C. Deser, and D. P. Schneider, 2014: Recent Antarctic sea ice trends in the context of Southern Ocean surface climate variations since 1950. Geophys. Res. Lett., 41, 2419-2426, doi:10.1002/2014GL059239.

Fogt, R. L., and D. H. Bromwich, 2006: Decadal variability of the ENSO teleconnection to the high-latitude South Pacific governed by coupling with the southern annular mode. J. Climate, 19, 979-997, doi:10.1175/JCLI3671.1.

Fyfe, J. C., and Coauthors, 2016: Making sense of the early-2000s warming slowdown. Nat. Climate Change, 6, 224-228, doi:10.1038/nclimate2938.

Gagné, M.-È., N. P. Gillett, and J. C. Fyfe, 2015: Observed and simulated changes in Antarctic sea ice extent over the past 50 years. Geophys. Res. Lett., 42, 90-95, doi:10.1002/2014GL062231.

Goosse, H., and V. Zunz, 2014: Decadal trends in the Antarctic sea ice extent ultimately controlled by ice-ocean feedback. Cryosphere, 8, 453-470, doi:10.5194/tc-8-453-2014.

Henley, B. J., J. Gergis, D. J. Karoly, S. Power, J. Kennedy, and C. K. Folland, 2015: A tripole index for the interdecadal Pacific oscillation. Climate Dyn., 45, 3077-3090, doi:10.1007/ s00382-015-2525-1.

Hobbs, W. R., N. L. Bindoff, and M. N. Raphael, 2015: New perspectives on observed and simulated Antarctic sea ice extent trends using optimal fingerprinting techniques. J. Climate, 28, 1543-1560, doi:10.1175/JCLI-D-14-00367.1. 
Holland, P. R., and R. Kwok, 2012: Wind-driven trends in Antarctic sea-ice drift. Nat. Geosci., 5, 872-875, doi:10.1038/ngeo1627.

Hoskins, B. J., and D. J. Karoly, 1981: The steady linear response of a spherical atmosphere to thermal and orographic forcing. $J$. Atmos. Sci., 38, 1179-1196, doi:10.1175/1520-0469(1981)038<1179: TSLROA $>2.0 . \mathrm{CO} ; 2$.

Irving, D., and I. Simmonds, 2016: A new method for identifying the Pacific-South American pattern and its influence on regional climate variability. J. Climate, 29, 6109-6125, doi:10.1175/JCLI-D-15-0843.1.

Jin, D., and B. P. Kirtman, 2009: Why the Southern Hemisphere ENSO responses lead ENSO. J. Geophys. Res., 114, D23101, doi:10.1029/2009JD012657.

Kosaka, Y., and S.-P. Xie, 2013: Recent global-warming hiatus tied to equatorial Pacific surface cooling. Nature, 501, 403-407, doi:10.1038/nature12534.

Lee, T., and M. J. McPhaden, 2008: Decadal phase change in large-scale sea level and winds in the Indo-Pacific region at the end of the 20th century. Geophys. Res. Lett., 35, L01605, doi:10.1029/2007GL032419.

L'Heureux, M. L., and D. W. J. Thompson, 2006: Observed relationships between the El-Niño-Southern Oscillation and the extratropical zonal-mean circulation. J. Climate, 19, 276-287, doi:10.1175/JCLI3617.1.

Li, X., D. M. Holland, E. P. Gerber, and C. Yoo, 2014: Impacts of the north and tropical Atlantic Ocean on the Antarctic Peninsula and sea ice. Nature, 505, 538-542, doi:10.1038/nature12945.

_, E. P. Gerber, D. M. Holland, and C. Yoo, 2015a: A Rossby wave bridge from the tropical Atlantic to West Antarctica. J. Climate, 28, 2256-2273, doi:10.1175/JCLI-D-14-00450.1.

— D. M. Holland, E. P. Gerber, and C. Yoo, 2015b: Rossby waves mediate impacts of tropical oceans on West Antarctic atmospheric circulation in austral winter. J. Climate, 28, 81518164, doi:10.1175/JCLI-D-15-0113.1.

Liu, J., J. A. Curry, and D. G. Martinson, 2004: Interpretation of recent Antarctic sea ice variability. Geophys. Res. Lett., 31, L02205, doi:10.1029/2003GL018732.

Mahlstein, I., P. R. Gent, and S. Solomon, 2013: Historical Antarctic mean sea ice area, sea ice trends, and winds in CMIP5 simulations. J. Geophys. Res. Atmos., 118, 5105-5110, doi:10.1002/jgrd.50443.

Matear, R. J., T. J. O'Kane, J. S. Risbey, and M. Chamberlain, 2015: Sources of heterogeneous variability and trends in Antarctic sea-ice. Nat. Commun., 6, 8656, doi:10.1038/ncomms9656.

McPhaden, M. J., T. Lee, and D. McClurg, 2011: El Niño and its relationship to changing background conditions in the tropical Pacific Ocean. Geophys. Res. Lett., 38, L15709, doi:10.1029/ 2011 GL048275.

Meehl, G. A., H. Teng, and J. M. Arblaster, 2014: Climate model simulations of the observed early-2000s hiatus of global warming. Nat. Climate Change, 4, 898-902, doi:10.1038/ nclimate2357.

_ J. M. Arblaster, C. M. Bitz, C. T. Y. Chung, and H. Teng, 2016a: Antarctic sea-ice expansion between 2000 and 2014 driven by tropical Pacific decadal climate variability. Nat. Geosci., 9, 590-595, doi:10.1038/ngeo2751.

_ - A. Hu, and H. Teng, 2016b: Initialized decadal prediction for transition to positive phase of the interdecadal Pacific oscillation. Nat. Commun., 7, 11718, doi:10.1038/ncomms11718.

Meier, W., F. Fetterer, M. Savoie, S. Mallory, R. Duerr, and J. Stroeve, 2015: NOAA/NSIDC climate data record of passive microwave sea ice concentration, version 2. National Snow and Ice Data Center, Boulder, CO, digital media. [Available online at http://nsidc.org/data/G02202/versions/2.]
Mo, K. C., 2000: Relationships between low-frequency variability in the Southern Hemisphere and sea surface temperature anomalies. J. Climate, 13, 3599-3610, doi:10.1175/ 1520-0442(2000)013<3599:RBLFVI >2.0.CO;2.

- , and R. W. Higgins, 1998: The Pacific-South American modes and tropical convection during the Southern Hemisphere winter. Mon. Wea. Rev., 126, 1581-1596, doi:10.1175/ 1520-0493(1998)126<1581:TPSAMA > 2.0.CO;2.

Newman, M., and Coauthors, 2016: The Pacific decadal oscillation, revisited. J. Climate, 29, 4399-4427, doi:10.1175/JCLI-D-15-0508.1.

Parkinson, C. L., and D. J. Cavalieri, 2012: Antarctic sea ice variability and trends, 1979-2010. Cryosphere, 6, 871-880, doi:10.5194/tc-6-871-2012.

Polvani, L. M., and K. L. Smith, 2013: Can natural variability explain observed Antarctic sea ice trends? New modeling evidence from CMIP5. Geophys. Res. Lett., 40, 3195-3199, doi:10.1002/grl.50578.

Purich, A., T. Cowan, S.-K. Min, and W. Cai, 2013: Autumn precipitation trends over Southern Hemisphere midlatitudes as simulated by CMIP5 models. J. Climate, 26, 8341-8356, doi:10.1175/JCLI-D-13-00007.1.

, W. Cai, M. H. England, and T. Cowan, 2016: Evidence for link between modelled trends in Antarctic sea ice and underestimated westerly wind changes. Nat. Commun., 7, 10409, doi:10.1038/ncomms10409.

Raphael, M. N., and Coauthors, 2016: The Amundsen Sea low: Variability, change, and impact on Antarctic climate. Bull. Amer. Meteor. Soc., 97, 111-121, doi:10.1175/BAMS-D-14-00018.1.

Rayner, N. A., D. E. Parker, E. B. Horton, C. K. Folland, L. V. Alexander, D. P. Rowell, E. C. Kent, and A. Kaplan, 2003: Global analyses of sea surface temperature, sea ice, and night marine air temperature since the late nineteenth century. J. Geophys. Res., 108, 4407, doi:10.1029/2002JD002670.

Renwick, J. A., 2002: Southern Hemisphere circulation and relations with sea ice and sea surface temperature. J. Climate, 15, 3058-3068, doi:10.1175/1520-0442(2002)015<3058: SHCARW $>2.0 . \mathrm{CO} ; 2$.

Saenko, O. A., J. C. Fyfe, N. C. Swart, W. G. Lee, and M. H. England, 2016: Influence of tropical wind on global temperature from months to decades. Climate Dyn., 47, 2193-2203, doi:10.1007/s00382-015-2958-6.

Schneider, D. P., C. Deser, and Y. Okumura, 2012: An assessment and interpretation of the observed warming of West Antarctica in the austral spring. Climate Dyn., 38, 323-347, doi:10.1007/s00382-010-0985-x.

Shields, C. A., D. A. Bailey, G. Danabasoglu, M. Jochum, J. T. Kiehl, S. Levis, and S. Park, 2012: The low-resolution CCSM4. J. Climate, 25, 3993-4014, doi:10.1175/JCLI-D-11-00260.1.

Sigmond, M., and J. C. Fyfe, 2016: Tropical Pacific impacts on cooling North American winters. Nat. Climate Change, 6, 970974, doi:10.1038/nclimate3069.

Simpkins, G. R., L. M. Ciasto, D. W. J. Thompson, and M. H. England, 2012: Seasonal relationships between large-scale climate variability and Antarctic sea ice concentration. J. Climate, 25, 5451-5469, doi:10.1175/JCLI-D-11-00367.1.

, S. McGregor, A. S. Taschetto, L. M. Ciasto, and M. H. England, 2014: Tropical connections to climatic change in the extratropical Southern Hemisphere: The role of Atlantic SST trends. J. Climate, 27, 4923-4936, doi:10.1175/JCLI-D-13-00615.1.

Stammerjohn, S. E., D. G. Martinson, R. C. Smith, X. Yuan, and D. Rind, 2008: Trends in Antarctic annual sea ice retreat and advance and their relation to El Niño-Southern Oscillation and southern annular mode variability. J. Geophys. Res., 113, C03S90, doi:10.1029/2007JC004269. 
_ R. Massom, D. Rind, and D. Martinson, 2012: Regions of rapid sea ice change: An inter-hemispheric seasonal comparison. Geophys. Res. Lett., 39, L06501, doi:10.1029/2012GL050874.

Swart, N. C., and J. C. Fyfe, 2013: The influence of recent Antarctic ice sheet retreat on simulated sea ice area trends. Geophys. Res. Lett., 40, 4328-4332, doi:10.1002/grl.50820.

Turner, J., 2004: The El Niño-Southern Oscillation and Antarctica. Int. J. Climatol., 24, 1-31, doi:10.1002/joc. 965.

_- , and Coauthors, 2009: Non-annular atmospheric circulation change induced by stratospheric ozone depletion and its role in the recent increase of Antarctic sea ice extent. Geophys. Res. Lett., 36, L08502, doi:10.1029/ 2009GL037524.

, T. J. Bracegirdle, T. Phillips, G. J. Marshall, and J. S. Hosking, 2013: An initial assessment of Antarctic sea ice extent in the CMIP5 models. J. Climate, 26, 1473-1484, doi:10.1175/JCLI-D-12-00068.1.
— J. S. Hosking, G. J. Marshall, T. Phillips, and T. J. Bracegirdle, 2016: Antarctic sea ice increase consistent with intrinsic variability of the Amundsen Sea low. Climate Dyn., 46, 2391-2402, doi:10.1007/s00382-015-2708-9.

Ummenhofer, C. C., A. Sen Gupta, and M. H. England, 2009: Causes of late twentieth-century trends in New Zealand precipitation. J. Climate, 22, 3-19, doi:10.1175/2008JCLI2323.1.

$\mathrm{Yu}, \mathrm{L}$., and Coauthors, 2011: Interpretation of recent trends in Antarctic sea ice concentration. J. Appl. Remote Sens., 5, 053557, doi:10.1117/1.3643691.

Yuan, X., and D. G. Martinson, 2000: Antarctic sea ice extent variability and its global connectivity. J. Climate, 13, 1697-1717, doi:10.1175/1520-0442(2000)013<1697:ASIEVA>2.0.CO;2.

Zunz, V., H. Goosse, and F. Massonnet, 2013: How does internal variability influence the ability of CMIP5 models to reproduce the recent trend in Southern Ocean sea ice extent? Cryosphere, 7, 451-468, doi:10.5194/tc-7-451-2013. 